\title{
Alpha-linolenic acid stabilizes HIF-1 $\alpha$ and downregulates FASN to promote mitochondrial apoptosis for mammary gland chemoprevention
}

\author{
Subhadeep Roy ${ }^{1}$, Atul Kumar Rawat ${ }^{2}$, Shreesh Raj Sammi ${ }^{3}$, Uma Devi ${ }^{4}$, Manjari \\ Singh ${ }^{1}$, Swetlana Gautam ${ }^{1}$, Rajnish Kumar Yadav ${ }^{1}$, Jitendra Kumar Rawat ${ }^{1}$, \\ Lakhveer Singh ${ }^{1}$, Mohd. Nazam Ansari ${ }^{5}$, Abdulaziz S. Saeedan ${ }^{5}$, Rakesh Pandey ${ }^{3}$, \\ Dinesh Kumar ${ }^{2}$ and Gaurav Kaithwas ${ }^{1}$ \\ ${ }^{1}$ Department of Pharmaceutical Sciences, Babasaheb Bhimrao Ambedkar University, Lucknow (UP), India \\ ${ }^{2}$ Central for Biomedical Research, Sanjay Gandhi Post Graduate Institute of Medical Sciences Campus, Lucknow (UP), India \\ ${ }^{3}$ Department of Microbial Technology and Nematology, CSIR-Central Institute of Medicinal and Aromatic Plants, Lucknow \\ (UP), India \\ ${ }^{4}$ Department of Pharmaceutical Sciences, Faculty of Health and Medical Sciences, Sam Higginbottom Institute of Agricultural \\ Sciences and Technology, Allahabad (UP), India \\ ${ }^{5}$ Department of Pharmacology, College of Pharmacy, Prince Sattam Bin Abdulaziz University, Al-Kharj, KSA \\ Correspondence to: Gaurav Kaithwas, email: gauravpharm@hotmail.com
}

Keywords: alpha linolenic acid, apoptosis, polyunsaturated fatty acid, hypoxia, fatty acid synthase

Received: February 06, $2017 \quad$ Accepted: June 12, $2017 \quad$ Published: July 25, 2017

Copyright: Roy et al. This is an open-access article distributed under the terms of the Creative Commons Attribution License 3.0 (CC BY 3.0), which permits unrestricted use, distribution, and reproduction in any medium, provided the original author and source are credited.

\section{ABSTRACT}

Alpha linolenic acid is an essential polyunsaturated fatty acid and is reported to have the anti-cancer potential with no defined hypothesis or mechanism/s. Henceforth present study was in-quested to validate the effect of alpha linolenic acid on mitochondrial apoptosis, hypoxic microenvironment and de novo fatty acid synthesis using in-vitro and in-vivo studies. The $\mathrm{IC}_{50}$ value of alpha linolenic acid was recorded to be $17.55 \mu \mathrm{M}$ against ER+MCF-7 cells. Treatment with alpha linolenic acid was evident for the presence of early and late apoptotic signals along with mitochondrial depolarization, when studied through acridine orange/ethidium bromide and JC-1 staining. Alpha linolenic acid arrested the cell cycle in G2/M phase. Subsequently, the in-vivo efficacy was examined against 7,12 -dimethylbenz anthracene induced carcinogenesis. Treatment with alpha linolenic acid demarcated significant effect upon the cellular proliferation as evidenced through decreased in alveolar bud count, restoration of the histopathological architecture and loss of tumor micro vessels. Alpha linolenic acid restored the metabolic changes to normal when scrutinized through ${ }^{1} \mathrm{H}$ NMR studies. The immunoblotting and QRT-PCR studies revealed participation of mitochondrial mediated death apoptosis pathway and curtailment of hypoxic microenvironment after treatment with alpha linolenic acid. With all above, it was concluded that alpha linolenic acid mediates mitochondrial apoptosis, curtails hypoxic microenvironment along with inhibition of de novo fatty acid synthesis to impart anticancer effects.

\section{INTRODUCTION}

$\alpha$-Linolenic acid (ALA) $(18: 3, \omega-3)$ is an essential polyunsaturated fatty acid (PUFA). ALA (18: 3, $\omega$-3) cannot be synthesized by the human body and needs to be obtained from dietary sources [1]. ALA is the major plant-based PUFA and is found in walnuts, flaxseeds, hemp seeds and their oils. ALA is also found in rapeseed (canola) oil; and 
to smaller amounts in soya oil and green-leafy vegetables [2]. ALA is metabolized by series of desaturation and elongation reactions of long chain fatty acids, among which eicosapentanoic acid (EPA, 20:5, $\omega$-3) and docosahexaenoic acid (DHA, 22:6 $\omega-3$ ) are of prime biological importance [3]. EPA and DHA are vital in regulating membrane fluidity, protein and cellular functions, eicosanoid metabolism, gene expression and cell signaling [4]. EPA and DHA are obtained from fish oil or derived from plant lipids rich in ALA. EPA and DHA integrate a cascade that runs alongside and emulates with the inflammatory cascade governed by the arachidonic acid (AA) $(20: 4, \omega-6)$ metabolism [5]. A previous report has taken account that the EPA cascade softens the inflammatory effects of AA cascade, suggesting it as an anti-inflammatory agent [6].

Report have also elaborated that $\omega-3$ fatty acids reduce prostate tumor growth, curtail histopathological progression and increase survival [7]. One of the previous study has also indicated that ALA actively suppresses the overexpression of HER2+ in mammary carcinomas [8]. It was also reported that overiectomized mice produce a significant reduction in tumor growth, when compared with a diet containing no flaxseed oil (rich source of
ALA)[9]. Moreover, PUFAs are the integral component of cell membranes and are susceptible to peroxidation and degeneration causing genetic mutations, a critical mechanism for tumor growth [10].Therefore, ALA seems to be a promising chemotherapeutic agent with desirable characteristics. Although studies have reported anticarcinogenic potential of ALA and ALA being a PUFA can moderate the cell membrane integrity in multiple ways, the mechanistic pathway behind the same is unanswered. Considering the same, the present study was proposed to explore the effects of ALA on mammary gland carcinoma with concomitant efforts to elucidate the possible mechanism beneath the same.

\section{RESULTS}

\section{MTT}

ALA $(1 \mu \mathrm{M}, 5 \mu \mathrm{M}, 10 \mu \mathrm{M}, 15 \mu \mathrm{M}, 20 \mu \mathrm{M}, 25 \mu \mathrm{M})$ significantly inhibited the growth of $\mathrm{ER}+\mathrm{MCF}-7$ cells in the dose dependent manner. The $\mathrm{IC}_{50}$ of ALA was calculated to be $17.55 \mu \mathrm{M}$ against ER+MCF-7 cells (Figure 1).

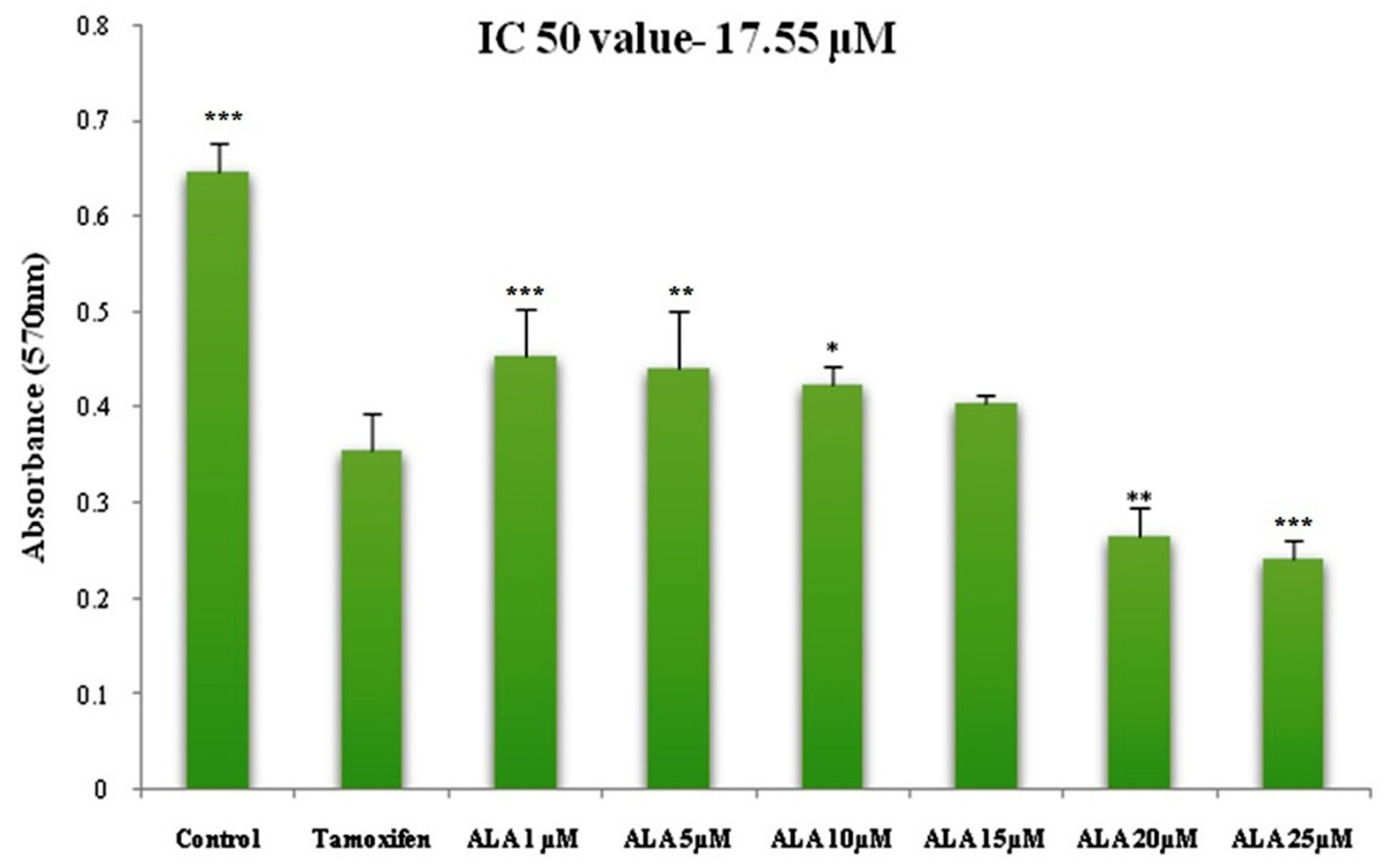

Figure 1: Cytotoxicity assessment of ALA. Histogram reveals the effect of ALA $(1 \mu \mathrm{M}, 5 \mu \mathrm{M}, 10 \mu \mathrm{M}, 15 \mu \mathrm{M}, 20 \mu \mathrm{M}$ and $25 \mu \mathrm{M})$ on cell cytotoxicity by MTT assay on ER+MCF-7 cell line after $24 \mathrm{~h}$ incubation. The O.D. at $570 \mathrm{~nm}$ was compared with the untreated cell and TMX $(27 \mu \mathrm{M})$ treated cells. Reduction in the O.D. at $570 \mathrm{~nm}$ was observed in a dose dependent manner. Values are presented as mean $\pm \mathrm{SD}$ and denote significant decreased in O.D. at $570 \mathrm{~nm}$ from control values. The comparisons are made by one-way ANOVA followed by Bonferroni multiple test. 


\section{Morphological studies for detection of apoptosis}

Fluorescence microscopic observations of the ER+MCF-7cells stained with acridine orange/ethidium bromide $(\mathrm{AO} / \mathrm{EtBr})$ (color-red or orange), revealed the presence of early and late apoptotic signals, including chromatin condensation, apoptotic body formation, membrane blebbing and fragmented nuclei. $\mathrm{AO} / \mathrm{EtBr}$ staining affirmed late and early apoptotic changes in the ER+ MCF-7 cells induced by ALA treatment (Figure 2).

\section{Measurement of mitochondrial membrane potential}

JC-1 is a cationic dye used to study mitochondrial depolarization. Mitochondrial depolarization is indicated by increase in green fluorescence intensity and decrease in orange intensity due to failure in intracellular accumulation of J-aggregates and their monomeric form. This represents disruption of active mitochondrial membrane and loss of conformation in mitochondria permeability transition pore (MPTP). Treatment with ALA increased the uptake of JC-1 in cells, which was visualized through increase in green fluorescence intensity suggesting early apoptotic mitochondrial depolarization $(\Delta \psi)$ (Figure 3).

\section{Cell cycle analysis using propidium iodide (PI)}

Flow cytometric analysis showed that treatment with $1 / 2 \mathrm{IC}_{50}$ dose of ALA increased the DNA content by 1.20 fold than that of control in G0/G1 phase (P3). ALA also increased apoptotic cell burden by 2.07 fold in apoptotic phase (P6). ALA treatment was evident for the cell death in S (P4) and G2/M (P5), along with increase in the apoptotic cell burden by 7.86 fold. The results indicated that ALA treatment arrested the cell cycle in G2/M phase (Figure 4).

\section{Annexin-V FITC dot assay}

Double labeling technique was used in flow cytometric analysis by using annexin-V FITC and PI. Lower left quadrant (Q1) is regarded as the population of live cells, lower right quadrant (Q2) is considered as the cell population at early apoptotic stage, upper right (Q3) quadrant represents the cell population at late apoptotic stage and upper left (Q4) quadrant is considered as necrotic cell population. Flow cytometric data analysis revealed that after $18 \mathrm{~h}$ of treatment with $1 / 2 \mathrm{IC}_{50}$ and $\mathrm{IC}_{50}$ dose of ALA, ER+MCF-7 cells were in LR quadrant (Q2) in a dose dependent manner(4.58\% against $2.42 \%$ ) (Figure 5).

\section{Hemodynamic studies}

Electrocardiogram (ECG) analysis revealed an increase in heart rate (HR) after 7, 12-Dimethylbenz (a) anthracene (DMBA) treatment (353.2 \pm 0.42 beats/ min). Treatment with ALA helped to restore the HR significantly close to normal ( $297.8 \pm 0.79$ beats $/ \mathrm{min})$. No significant variability was recorded in the $\mathrm{P}$ wave duration after either of the treatments (Supplementary Figure 1, Supplementary Table 1). The heart rate variability (HRV) analysis of the ECG complex revealed the sharp decrease in the low frequency (LF) $\left(9.24 \pm 0.01 \mathrm{~ms}^{2}\right)$, high frequency (HF) $\left(37.77 \pm 0.05 \mathrm{~ms}^{2}\right)$ and very low frequency (VLF) $\left(41.41 \pm 0.08 \mathrm{~ms}^{2}\right)$ after the DMBA treatment. Treatment with ALA perceived dose-dependent restoration of the HRV parameters (Table 1).

\section{Morphological evaluation}

\section{Carmine staining of whole mount's mammary gland}

In the DMBA treated group, there was marked increase in the lobules and alveolar buds (AB) count, representing cellular proliferation and ALA afforded a marked protection against the same. As a marker for growth and proliferation of the mammary gland tissue, ALA also decreased the differentiation score favorably (Figure 6A-6D).

\section{Hematoxyline \& Eosin staining of mammary gland tissue}

The histopathological examination of the control tissue elaborated presence of duct; adipocytes; loose connective tissue (LCT); dense connective tissue (DCT); myoepithelial cells (MEC); lymphocytes and cuboidal epithelial cells (CEC) (Figure 6E). Treatment with DMBA recorded loss of duct, adipocytes, LCT, DCT and lymphocytes along with scattered CEC (Figure 6F). Infact, DMBA treatment distorted the histological architecture of the mammary gland tissue. Concomitant treatment with ALA imparted dose dependent restoration of the cellular architecture close to control (Figure 6G, 6H).

\section{Scanning electron microscopy (SEM) of mammary gland tissue}

The control tissue was evident for the features like intra-arterial cushion/collagenous covering, collagen layer and duct (Figure 6I). DMBA treatment evidenced loss of intra-arterial cushion (Figure 6J); development of small tumor micro-vessels and development of nodules (Figure $6 \mathrm{~J})$. Subsequent ALA administration perceived decrease in tumor micro-vessel formation, representing the deep impression of ALA on the branching sites along with restoration of intra-arterial cushion (Figure 6K, 6L).

\section{Antioxidant markers}

Treatment with ALA validated the restoration of the antioxidant defense system in comparison to DMBA treated group. The protein and lipid peroxidation was very well evident after DMBA treatment. The ALA successfully 


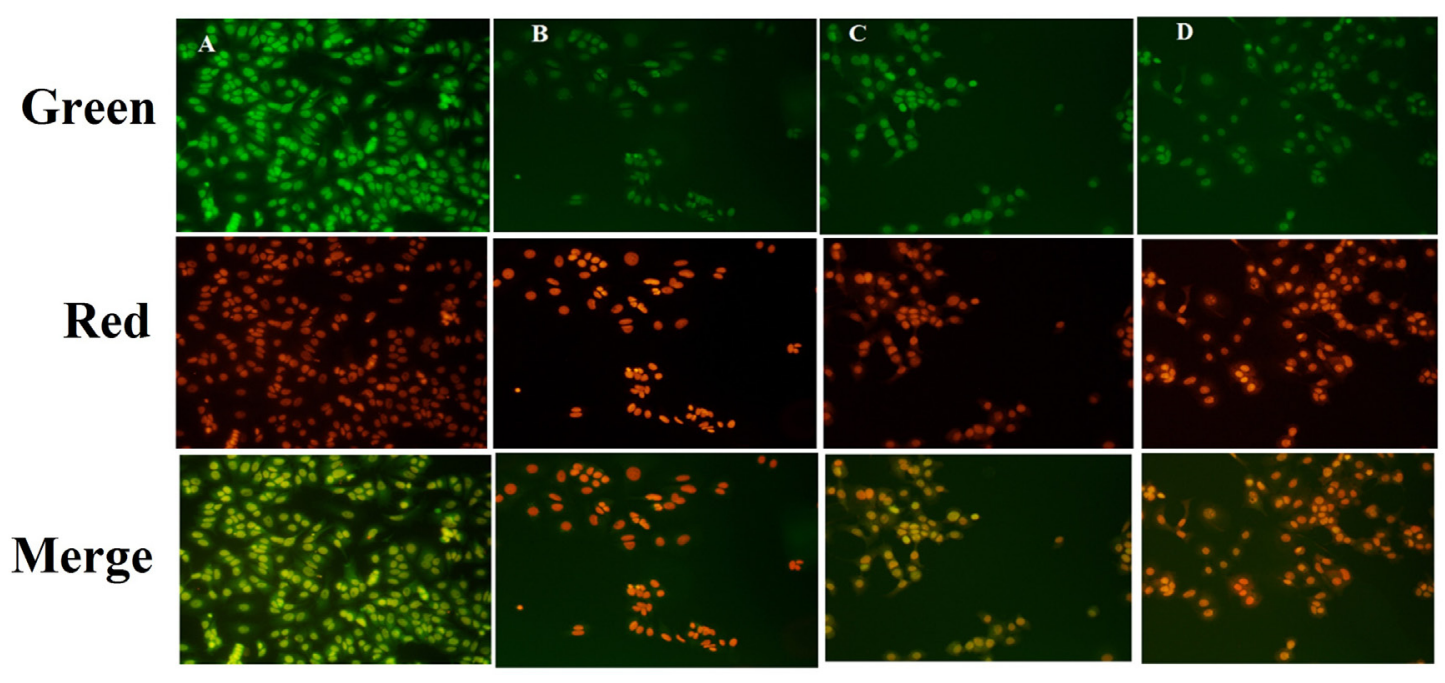

Figure 2: Effect of ALA on early apoptotic changes studied through AO/EtBr staining. In fluorescence microscopic study of

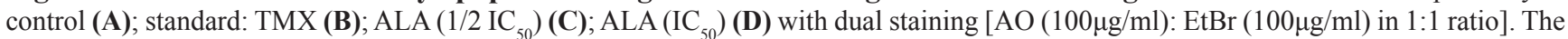
fluorescence was measured in three respective channels (green, red and merged) with 20X magnification, which reveals the morphological changes of apoptosis in experimental procedure after $18 \mathrm{~h}$ drug treatment.
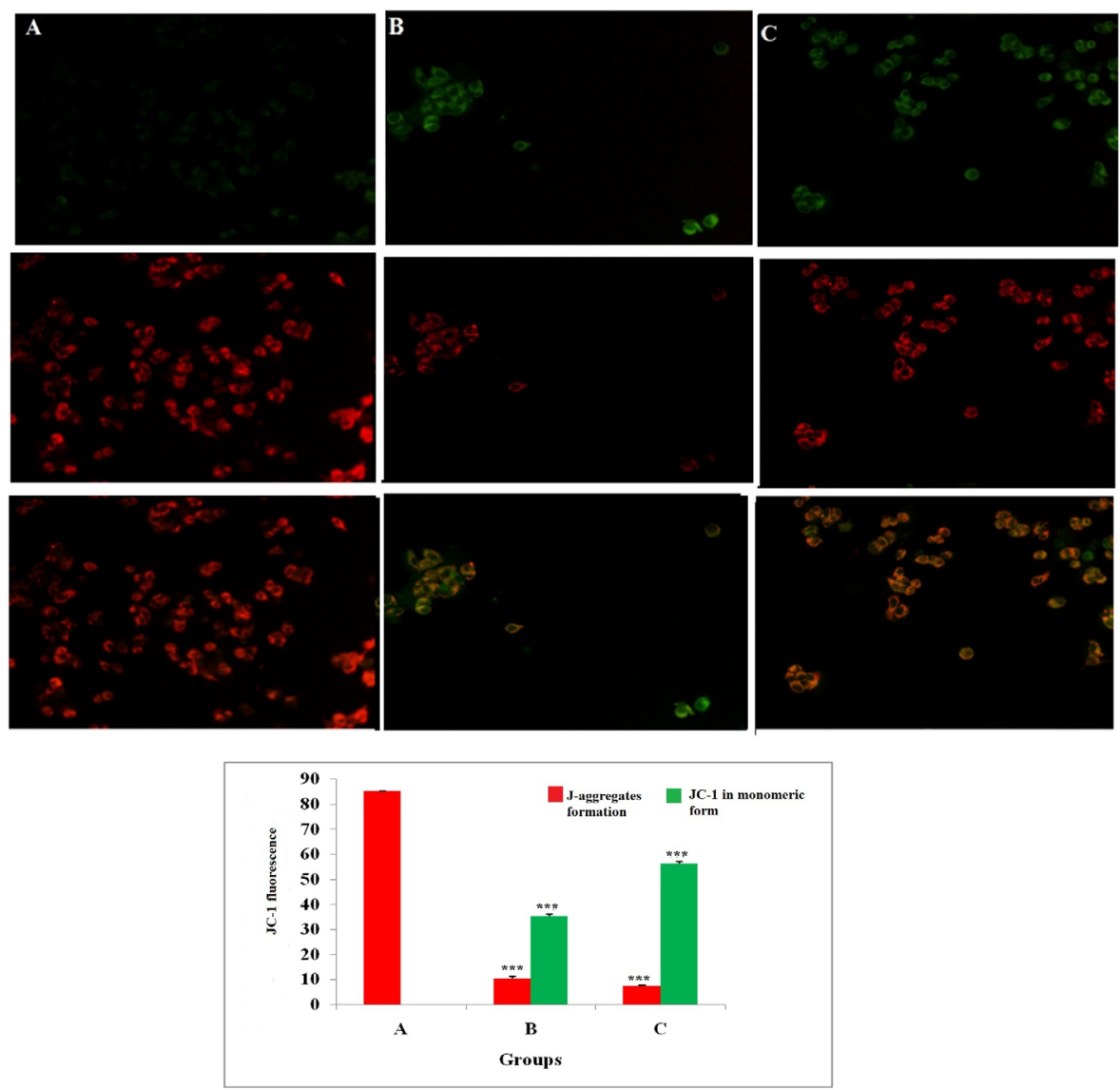

Figure 3: Effect of ALA on mitochondrial membrane potential ( $\Delta \boldsymbol{\psi})$. ER+MCF-7 cells treated with control (A); ALA (1/2 IC $\left.{ }_{50}\right)$ (B); $\mathrm{ALA}\left(\mathrm{IC}_{50}\right)$ (C) for $18 \mathrm{~h}$ and proceeded with JC-1 dye $(5 \mathrm{mg} / \mathrm{ml})$ for $1 \mathrm{~h}$. The cells were examined under inverted fluorescence microscope in three respective channels (green, red and merged). Internal accumulations of JC-1 aggregate in apoptotic cells are represented through change in ratio of orange to green fluorescence intensity in merged channel. Values are presented as mean $\pm \mathrm{SD}$ and the comparisons are made on the basis of one-way ANOVA followed by Bonferroni multiple test. 
decreased the level of protein carbonyl (PC) $(32.95 \pm 0.9$ $\mathrm{nM} / \mathrm{ml}$ unit). Significant changes in the thiobarbituric acid reactive substances (TBARs) $(0.21 \pm 0.02 \mathrm{nM}$ of $\mathrm{MDA} /$ $\mu \mathrm{g}$ of protein) were also observed after ALA treatment. The level of glutathione (GSH) in DMBA treated group $(1.03 \pm 0.09 \mathrm{mg} \%)$ was significantly restored after ALA treatment $(1.19 \pm 0.01 \mathrm{mg} \%)$. Corresponding to the levels of superoxide dismutase (SOD) $(0.037 \pm 0.01$ units of SOD $/ \mathrm{mg}$ of protein) and catalase (13.91 $\pm 0.97 \mathrm{nM}$ of $\mathrm{H} 2 \mathrm{O} 2 / \mathrm{min} / \mathrm{mg}$ of protein) in DMBA treated group;
ALA significantly accompanied to restore the same (i.e. $0.044 \pm 0.01$ units of SOD $/ \mathrm{mg}$ of protein and $22.00 \pm 0.90$ $\mathrm{nM}$ of $\mathrm{H} 2 \mathrm{O} 2 / \mathrm{mg}$ of protein) comparable to normal control (Table 2).

\section{${ }^{1}$ H-NMR method for serum metabolites profiling}

A typical ${ }^{1} \mathrm{H}$ CPMG NMR spectra of serum samples obtained from different groups is shown in Figure 7. The NMR spectra showed signals, mainly from lipids/
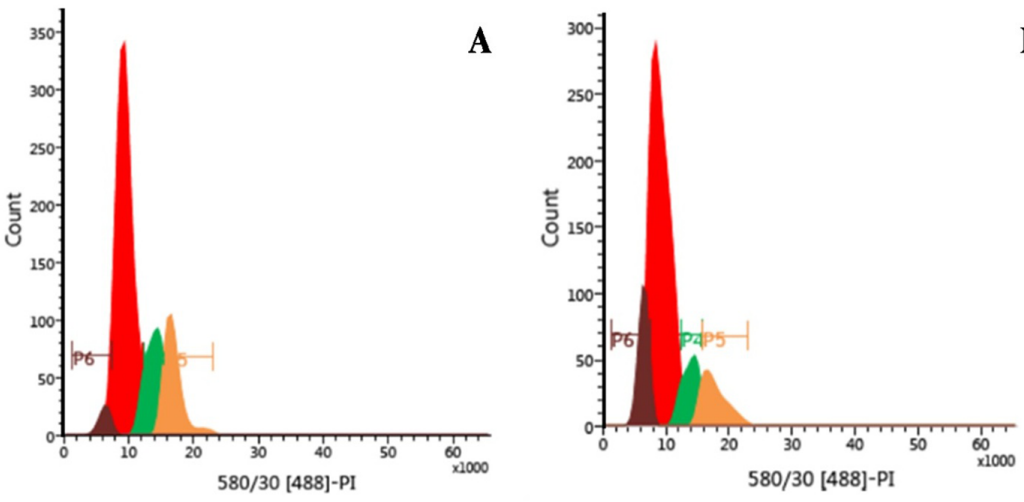

B
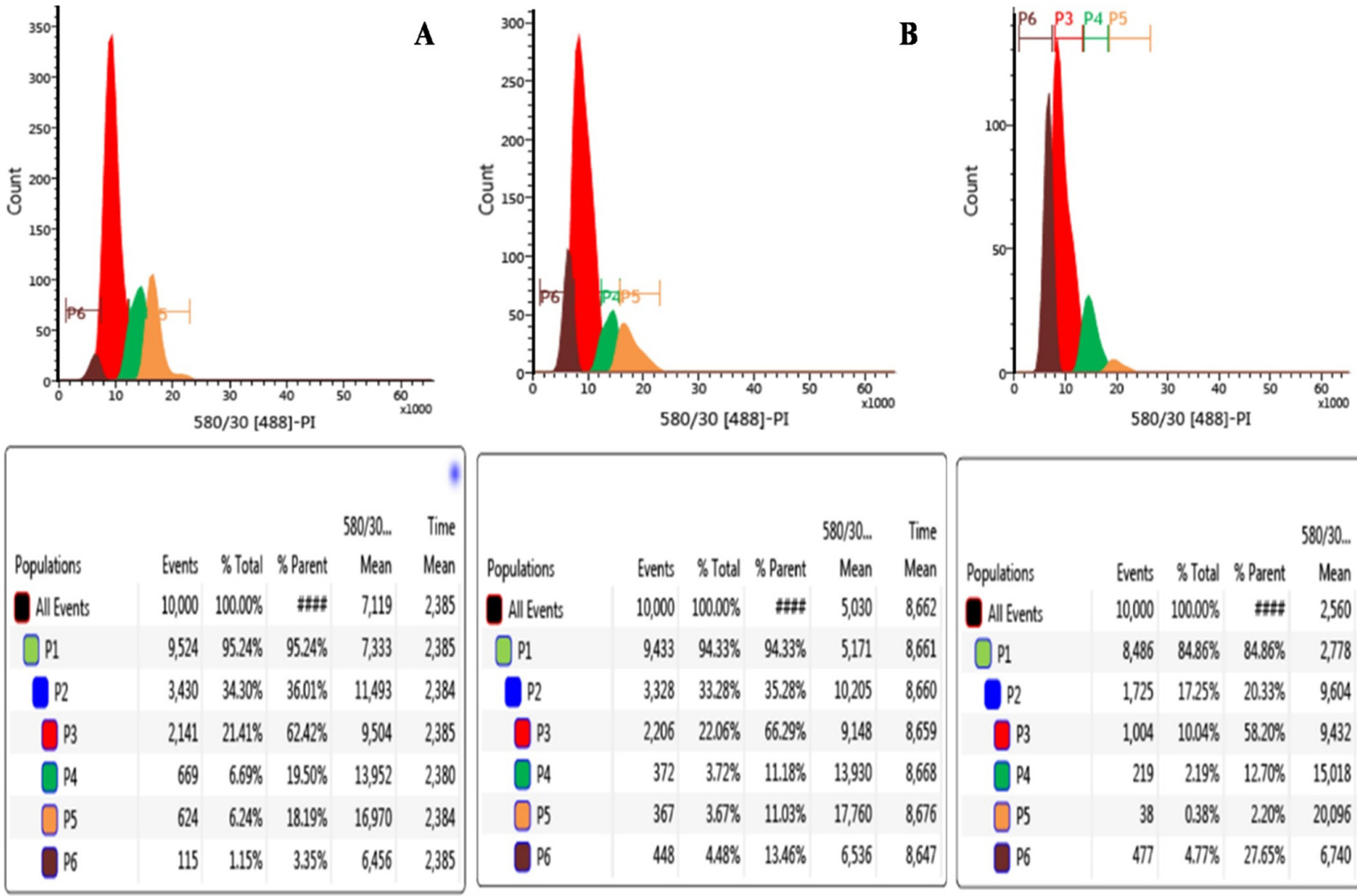

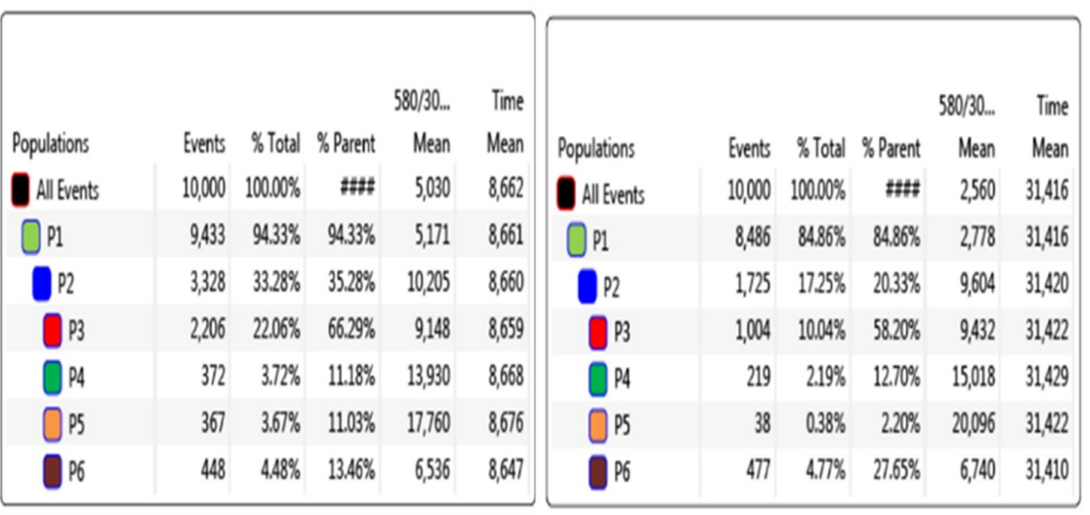

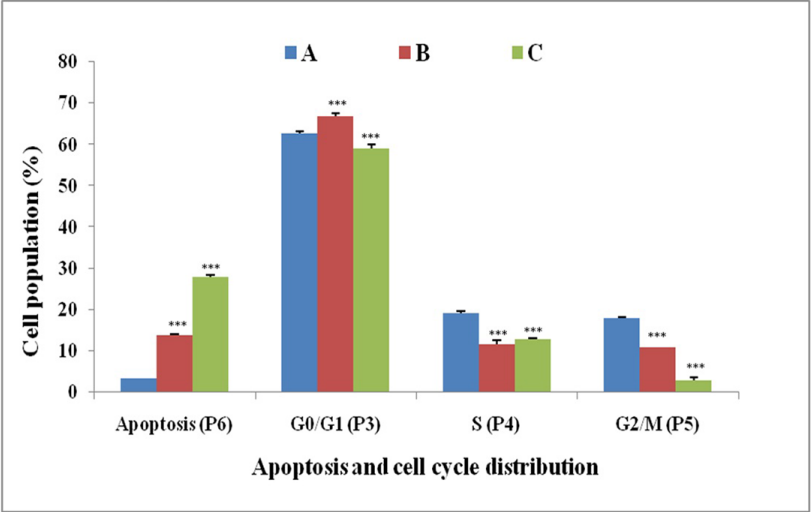

Figure 4: Effect of ALA on cell cycle arrest of ER+MCF-7 cells. Flow cytometric analysis of cell cycle phase distribution was performed in control (A); ALA $\left(1 / 2 \mathrm{IC}_{50}\right)(\mathbf{B})$; ALA $\left(\mathrm{IC}_{50}\right)(\mathbf{C})$ after $18 \mathrm{~h}$ of treatment using PI staining. The histogram represents various content of DNA with actual number of cell present in three stages G0/G1 (P3), S (P4) and G2/M (P5). (X axis denotes fluorescence intensity of PE Texas red and Y axis denotes count). Values are presented as mean $\pm \mathrm{SD}$ and the comparisons are made on the basis of one-way ANOVA followed by Bonferroni multiple test. 
lipoproteins [(e.g. low density lipoprotein (LDL), very low density lipoprotein (VLDL), PUFAs etc.)], membrane metabolites [(e.g. choline, phosphocholine (PC), and glycerophosphocholine (GPC)], N-acetyl and $\mathrm{O}$-acetyl glycoproteins (NAG, OAG), and amino acids [(e.g. leucine, isoleucine, valine, alanine, lysine, proline, glutamine, glutamate, histidine, tyrosine, and phenylalanine etc.)]. Other identified metabolites were, glucose, lactate, acetate, citrate, creatine and allantoin.

\section{Multivariate statistical analysis}

The multivariate data analysis was performed to find out specific metabolic changes induced by DMBA treatment and to further reveal the effect of ALA treatment on these metabolic alterations. The ${ }^{1} \mathrm{H}-\mathrm{NMR}$ dataset was analyzed using standard multivariate analysis methods including principal component analysis (PCA), partial least square discriminant analysis (PLS-DA), and OPLS-DA to study trends and show clusters among the groups (Figure 8A). First, unsupervised PCA score plots were constructed for an initial overview of the data set and identify the outlier samples (Figure 8a). The majority samples were located in $95 \%$ confidence interval. Therefore, all of the samples were used in the analysis to ensure the maximum information. Supervised PLS-DA score plots were generated to further improve the separation between the four groups. PLS-DA score plots showed that ALA treated groups were well separated from the normal control group,
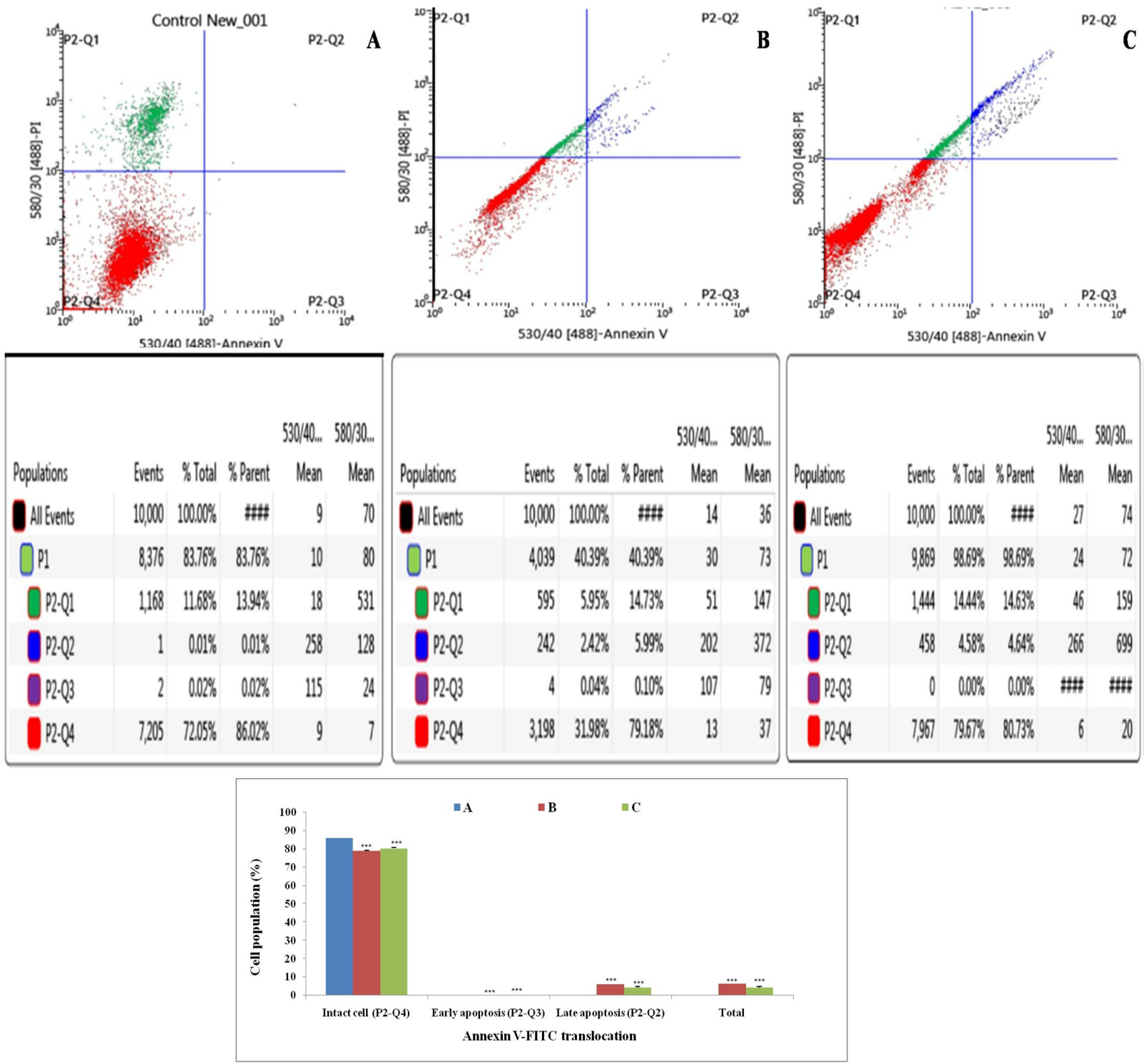

Figure 5: Effect of ALA on cell cycle arrest studied through Annexin-V FITC binding. Study represent detection of cycle arrest in the ER+MCF-7 cells treated with control (A); ALA (1/2 IC $\left.\mathrm{Cl}_{50}\right)(\mathbf{B})$; ALA $\left(\mathrm{IC}_{50}\right)(\mathbf{C})$. Cells were treated with Annexin V FITC and PI. Dual parameter dot plot of FITC-fluorescence ( $x$-axis) vs. PI-fluorescence ( $y$-axis) shows logarithmic intensity. Values are presented as mean $\pm \mathrm{SD}$ and the comparisons are made on the basis of one-way ANOVA followed by Bonferroni multiple test. 
Table 1: Effect of ALA on HRV changes in DMBA induced mammary gland carcinogenesis

\begin{tabular}{|c|c|c|c|c|}
\hline & $\begin{array}{c}\text { Control } \\
(0.9 \% \text { normal saline, } \\
\text { p.o })\end{array}$ & $\begin{array}{c}\text { Toxic control } \\
\text { (DMBA } 8 \mathrm{mg} / \mathrm{kg} \text { i.v) }\end{array}$ & $\begin{array}{c}\text { DMBA+ ALA } \\
(8 \mathrm{mg} / \mathrm{kg} \text { i.v. }+ \text { 0.25ml/ } \\
\text { kg, p.o. })\end{array}$ & $\begin{array}{c}\text { DMBA+ALA } \\
(8 \mathrm{mg} / \mathrm{kg} \text { i.v. }+0.5 \mathrm{ml} / \\
\text { kg, p.o. })\end{array}$ \\
\hline \multicolumn{5}{|c|}{ Time Domain } \\
\hline Average RR (ms) & $166.2 \pm 0.02 * * *$ & $172.1 \pm 0.02$ & $181.3 \pm 0.05 * * *$ & $165.5 \pm 0.01 * * *$ \\
\hline Median RR (ms) & $166.6 \pm 0.06 * * *$ & $172.8 \pm 0.05$ & $182.3 \pm 0.09 * * *$ & $165.5 \pm 0.09 * * *$ \\
\hline SDRR (ms) & $6.25 \pm 0.01 * * *$ & $3.66 \pm 0.7$ & $6.79 \pm 0.01 * * *$ & $5.63 \pm 0.01 * * *$ \\
\hline CVRR & $0.02 \pm 0.01$ & $0.02 \pm 0.01$ & $0.12 \pm 0.02 * * *$ & $0.18 \pm 0.02 * * *$ \\
\hline \multicolumn{5}{|c|}{ Frequency Domain } \\
\hline $\mathbf{L F}\left(\mathrm{ms}^{2}\right)$ & $11.32 \pm 0.06^{* * *}$ & $9.24 \pm 0.01$ & $14.02 \pm 0.04 * * *$ & $12.22 \pm 0.06 * * *$ \\
\hline $\mathrm{HF}\left(\mathrm{ms}^{2}\right)$ & $39.70 \pm 0.09 * * *$ & $37.77 \pm 0.05$ & $46.24 \pm 0.09 * * *$ & $43.30 \pm 0.07 * * *$ \\
\hline LF/HF & $0.34 \pm 0.02$ & $0.32 \pm 0.04$ & $0.24 \pm 0.08$ & $0.21 \pm 0.1 *$ \\
\hline VLF $\left(m s^{2}\right)$ & $42.13 \pm 0.07 * * *$ & $41.41 \pm 0.08$ & $38.47 \pm 0.04 * * *$ & $42.87 \pm 0.09 * * *$ \\
\hline
\end{tabular}

(Values are presented as Mean $\pm \mathrm{SD}$ ). Each group contains eight animals. Comparisons are made on the basis of the one-way ANOVA followed by Bonferroni multiple test. All groups are compared to the DMBA treated group $(* \mathrm{p}<0.05$, $* * \mathrm{p}<0.01, * * * \mathrm{p}<0.001)$.
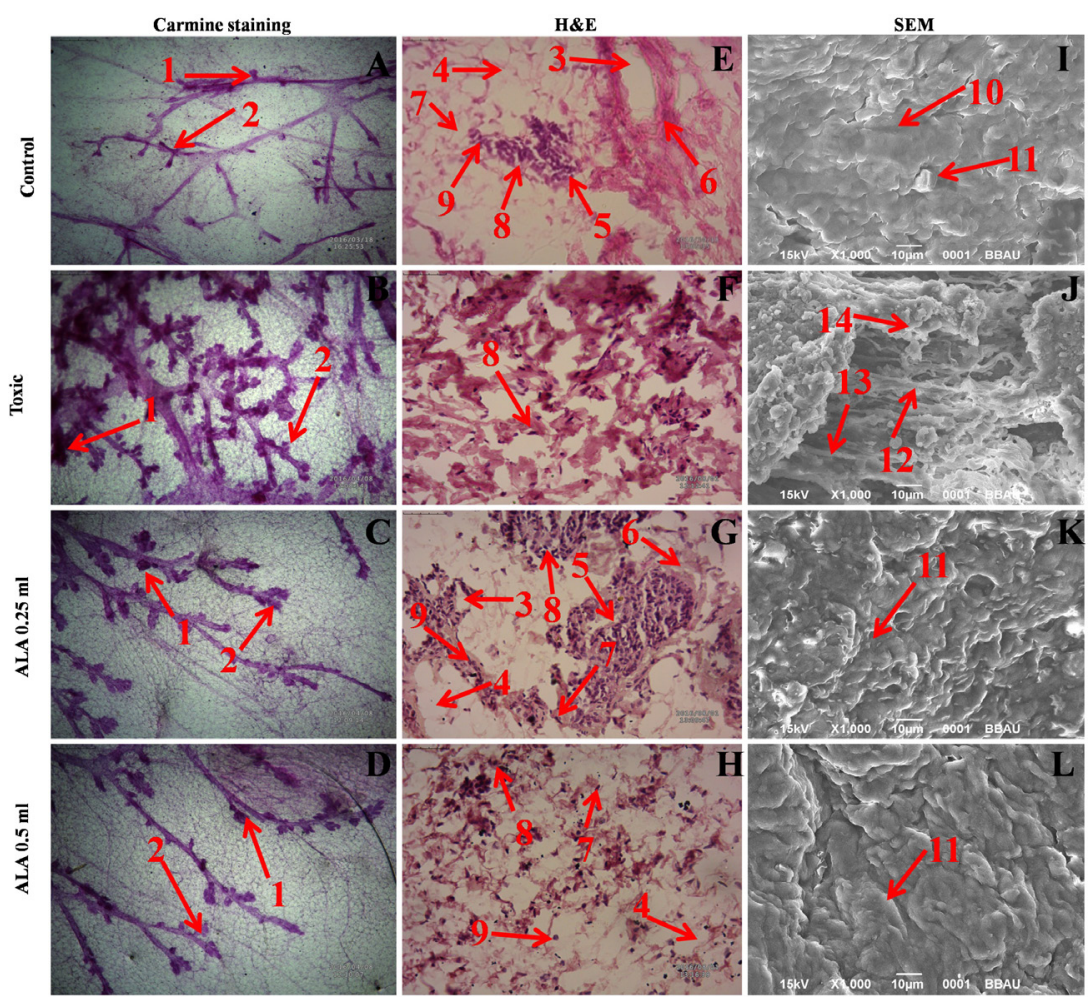

Figure 6: Microscopic evaluation of mammary gland tissue of the animal treated with ALA. Whole mount carmine alum staining of ductal epithelium reveals the presence of lobules (1) and $\mathrm{AB}$ (2) (A, B, C and D). The extent of AB and lobules formation was excessive in the DMBA treated group (B) which was subsided through respective treatment (C and D). H\&E staining of three respective groups (E, $\mathbf{G}$ and $\mathbf{H}$ ) revealed duct (3), adipocytes (4), LCT (5), DCT (6), MEC (7), lymphocytes (8) and CEC (9) in control as well as ALA treated groups $(\mathbf{E}, \mathbf{G}$ and $\mathbf{H})$. In DMBA treated group $(\mathbf{F})$, the cell morphology was distorted and cell organelles were absent. SEM analysis of control (I), DMBA treated $(\mathbf{J})$ and treatment group (K and $\mathbf{L})$ revealed the differences in collagen layer (10), duct (11), small capillary network (12) and nodules (13) in respective groups. 
Table 2: Effect of ALA on oxidative stress markers against DMBA induced mammary gland carcinoma

\begin{tabular}{|c|c|c|c|c|c|}
\hline Groups & $\begin{array}{c}\text { TBARs } \\
\text { (nM of MDA } / \mu \mathrm{g} \text { of } \\
\text { protein) }\end{array}$ & $\begin{array}{c}\text { GSH } \\
(\mathrm{mg} \%)\end{array}$ & $\begin{array}{c}\text { SOD } \\
\text { (Units of SOD/ } \\
\text { mg of protein) }\end{array}$ & $\begin{array}{c}\text { Catalase } \\
\left(\mathrm{nM} \text { of } \mathrm{H}_{2} \mathrm{O}_{2} / \mathrm{min} /\right. \\
\text { mg of protein) }\end{array}$ & $\begin{array}{c}\text { Protein } \\
\text { carbonyl } \\
(\mathbf{n M} / \mathbf{m l} \text { unit) }\end{array}$ \\
\hline $\begin{array}{l}\text { Control }(0.9 \% \text { normal } \\
\text { saline, p.o. })\end{array}$ & $0.15 \pm 0.03 * * *$ & $1.10 \pm 0.06^{* * *}$ & $0.042 \pm 0.01$ & $18.45 \pm 0.3 * * *$ & $40.43 \pm 0.11 * * *$ \\
\hline $\begin{array}{l}\text { Toxic control (DMBA } \\
8 \mathrm{mg} / \mathrm{kg} \text {, i.v.) }\end{array}$ & $0.30 \pm 0.02$ & $1.03 \pm 0.09$ & $0.037 \pm 0.01$ & $13.91 \pm 0.97$ & $45.57 \pm 0.92$ \\
\hline $\begin{array}{l}\text { DMBA +ALA ( } 8 \mathrm{mg} / \mathrm{kg} \text {, } \\
\text { i.v. }+0.25 \mathrm{ml} / \mathrm{kg}, \text { p.o. })\end{array}$ & $0.23 \pm 0.19 * * *$ & $1.11 \pm 0.02 * * *$ & $0.042 \pm 0.02$ & $19.60 \pm 0.03 * * *$ & $34.42 \pm 0.68 * * *$ \\
\hline $\begin{array}{l}\mathrm{DMBA}+\mathrm{ALA}(8 \mathrm{mg} / \mathrm{kg} \text {, } \\
\text { i.v. }+0.5 \mathrm{ml} / \mathrm{kg}, \text { p.o. })\end{array}$ & $0.21 \pm 0.02 * * *$ & $1.19 \pm 0.01 * * *$ & $0.044 \pm 0.01$ & $22.00 \pm 0.90 * * *$ & $32.95 \pm 0.9 * * *$ \\
\hline
\end{tabular}

(Values are Mean $\pm \mathrm{SD}$ ), each group contains eight animals. Comparisons are made on the basis of one-way Anova followed by Bonferroni test. All groups are compared to the DMBA treated group $(* \mathrm{p}<0.05, * * \mathrm{p}<0.01, * * * \mathrm{p}<0.001)$.

with a significantly higher quality of fit and predictability (i.e. R2, Q2>0.5, Figure 8b). Next, to minimize the possible contribution of intergroup variability and to improve the group discriminatory features, OPLS-DA was performed. As shown in Figure 8c, the OPLS-DA score plots depicted excellent grouping of samples within each group and improved separation for the different treatments with significantly well explained variation and predictive capability (i.e. R2Y, Q2>0.5, Figure 8c). The OPLS-DA score plot analysis further revealed that ALA $(0.25 \mathrm{ml} /$ $\mathrm{kg})$ and ALA $(0.5 \mathrm{ml} / \mathrm{kg})$ treatments are progressively mitigating the toxic effect of DMBA treatment as evident by the shifting of these groups within the control group.

To further reveal the biochemical effects produced by DMBA treatment and ascertain if ALA treatment could reset back these changes, the pairwise PLS-DA analysis with respect to normal control rats was performed. Figure $8 \mathrm{~B}$ shows the 2D score plots derived from PLS-DA analysis in each case (the corresponding PCA score plots are shown in Supplementary Figure 2). The quality and reliability parameters (R2 and Q2) assessed for each paired PLS-DA model (Figure 8B) were found to satisfactorily

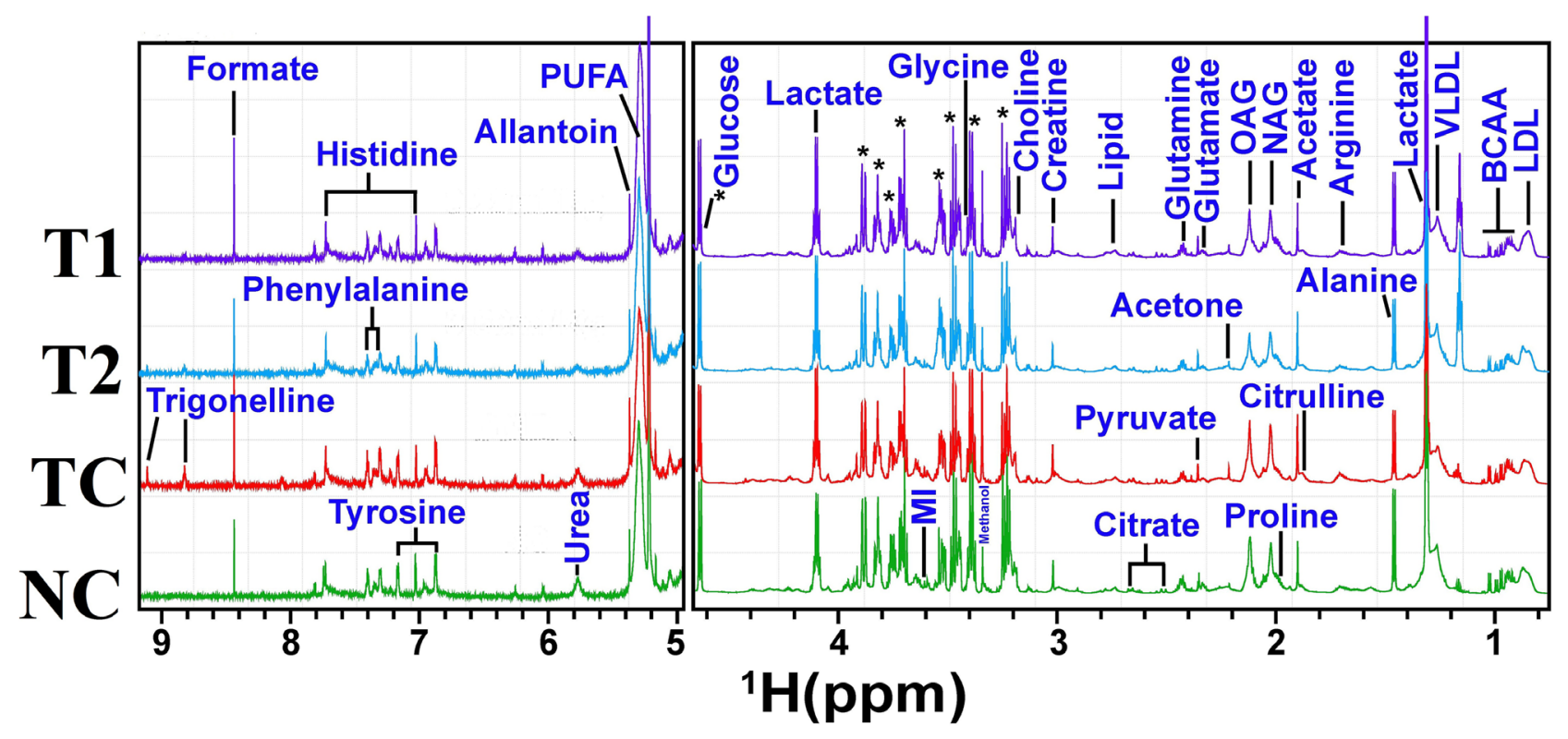

Figure 7: Stack plot of representative 1D ${ }^{1} \mathrm{H}$ NMR spectra of rat sera obtained from different groups. The representative1D ${ }^{1} \mathrm{H}$ CPMG NMR spectra of rat serum obtained from different groups. The peaks annotated in the figure shows the assignments of serum metabolites. Groups were differentiated as: normal control (NC), toxic control -DMBA (TC), ALA-0.25 ml/kg (T1) and ALA-0.5 ml/kg (T2). The abbreviations used are LDL/VLDL: low/very-low-density lipoproteins; PUFA: polyunsaturated fatty acids; BCAA: branched chain amino acids: isoleucine, leucine, valine; MI: myo-inositol, OAG: O-acetyl glycoproteins; NAG: N-acetyl glycoproteins. 
higher (R2, Q2>0.5) suggesting that PLS-DA can be employed to evaluate the biochemical effects of ALA treatment. Discriminatory (PLS-DA) analysis between DMBA treated, and normal control groups revealed twenty five metabolite entities significantly perturbed in DMBA treated group with respect to control, using VIP score $>1$ for discrimination significance (Supplementary Figure 3).

As listed in Table 3, twenty five metabolites were found to be significantly perturbed in the sera of DMBA treated rats compared with normal control rats. DMBA treated rats had elevated levels of lipids, VLDL/LDL lipoprotein, lactate, NAG, OAG, PUFA, arginine, citrulline, creatine, myo-inositol, glycine, allantoin, tyrosine, histidine, phenylalanine, formate and trigonelline in their sera. Moreover, decreased levels of glucose, choline/GPC, and several amino acids including, alanine, isoleucine, valine, glutamate and glutamine was recorded as well. Further, we found that the metabolic alterations which were observed in DMBA treated group were ameliorated after the ALA treatment as evident from the box plot (Figure 9).

\section{Assay for caspase 3 and caspase 8}

ALA $(0.25 \mathrm{ml} / \mathrm{kg})$ increased the levels of caspase 3 and caspase 8 in the DMBA treated animals significantly (Figure 10).

\section{Western blotting}

The expression of anti-apoptotic proteins (Bcl-2 and $\mathrm{Bcl}-\mathrm{xl}$ ) was increased after DMBA administration with vice versa effect upon pro-apoptotic markers (BAD and BAX). Treatment with ALA helped to restore the anti-apoptotic and pro-apoptotic markers favorably suggesting apoptosis. When perceived through the downstream markers of mitochondrial mediated apoptosis (VADC, cytochrome c, Apaf-1 and pro-caspase 9), the DMBA afforded increased expression of VDAC, Apaf-1 and pro-caspase9 along with curtailment of cytochrome c expression (Figure 11). Treatment with ALA afforded marked regulation of apoptotic markers favoring apoptosis. Treatment with DMBA also afforded commendable hypoxia as perceived through increased expression of NFкBp65, UCHL-1, HIF-1 $\alpha$, FASN and SREBP-1c; and decreased expression of PHD2. Concomitant ALA treatment afforded abatement of hypoxic markers significantly (Figure 12).

\section{qRT-PCR}

The genetic phenotypes for the protein markers for mitochondrial death pathway were validated through qRT-PCR assay (Figure 11). The findings from the
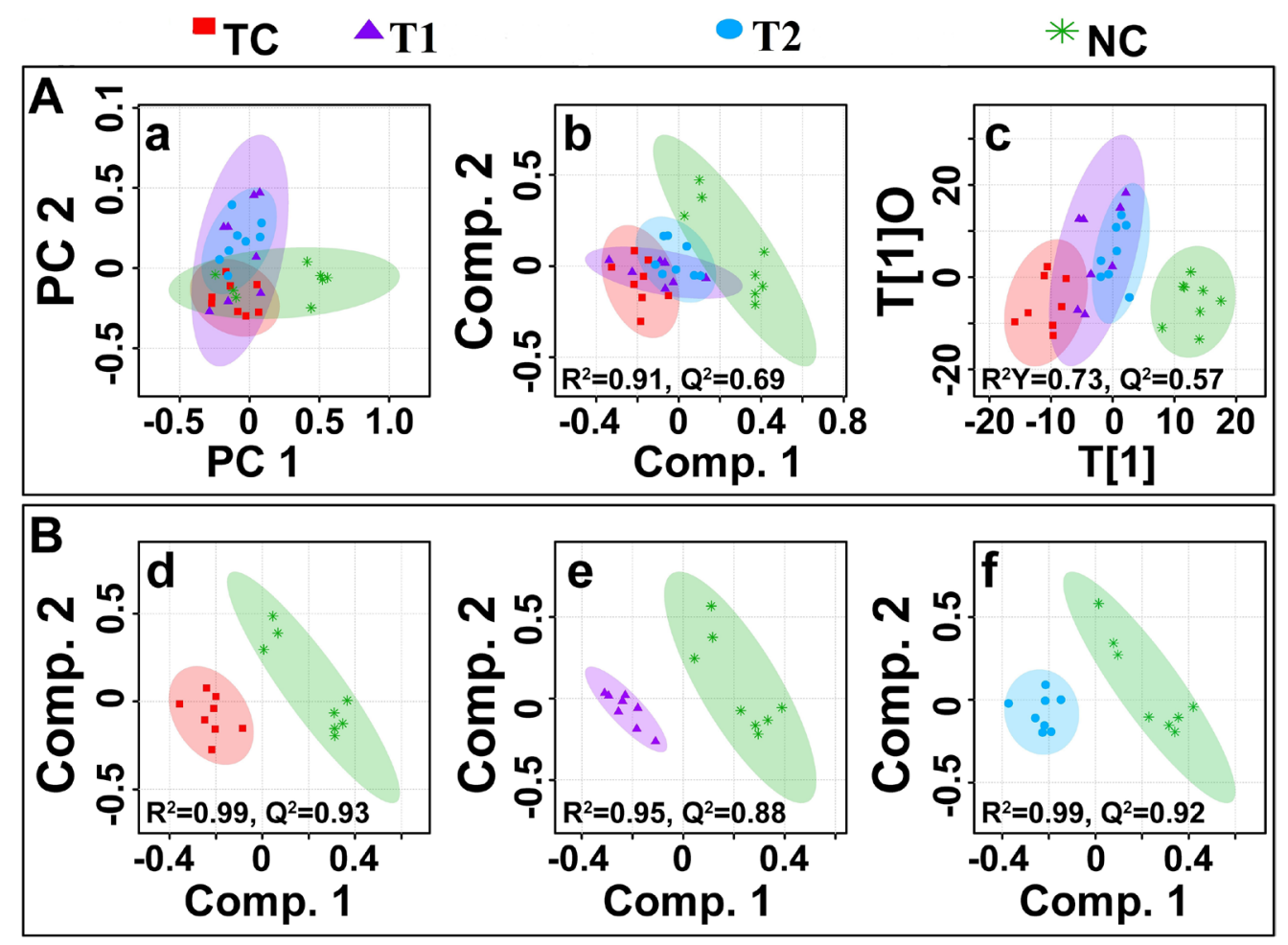

Figure 8: Multivariate analysis. (A) The combined2D PCA (a) and 2D PLS-DA (b) 2D OPLS-DA (c) score plots derived from cumulative analysis of $1 \mathrm{D}^{1} \mathrm{H}$ CPMG NMR spectra comprising of all the groups: normal control (NC), toxic control -DMBA (TC), ALA$0.25 \mathrm{ml} / \mathrm{kg}$ (T1) and ALA-0.5 ml $/ \mathrm{kg}$ (T2). Color circles indicate the 95\% confidence interval for each class (B). The pairwise PLS-DA score plots (d-f): (d) between normal control (NC) and DMBA treated toxic control (TC) group, (e) between NC and DMBA+0.25ml/kg-ALA, and (f) between NC vs DMBA+ALA- $0.5 \mathrm{ml} / \mathrm{kg}$. 
Table 3: Metabolic variabilities among the groups treated with DMBA and ALA when compared to normal control

\begin{tabular}{|c|c|c|c|c|c|}
\hline \multirow{2}{*}{ \# } & \multirow{2}{*}{${ }^{1} \mathrm{H}$ ppm } & \multirow{2}{*}{$\begin{array}{l}\text { Metabolite } \\
(\downarrow \uparrow)\end{array}$} & \multicolumn{3}{|c|}{ Control vs } \\
\hline & & & DMBA & ALA-0.25 & ALA-0.5 \\
\hline 1 & $0.825-0.885$ & LDL & $*(\uparrow)$ & $*(\uparrow \uparrow)$ & $*(\uparrow \uparrow \uparrow)$ \\
\hline 2 & $1.205-1.235$ & VLDL & $*(\uparrow)$ & $*(\uparrow \uparrow)$ & $*(\uparrow \uparrow \uparrow)$ \\
\hline 3 & $5.245-5.355$ & PUFA & $*(\uparrow)$ & $*(\uparrow)$ & $*(\uparrow \uparrow \uparrow)$ \\
\hline 4 & 0.985 & Isoleucine & $(\downarrow) \#$ & $*(\downarrow \downarrow)$ & $(\downarrow \downarrow \downarrow) \#$ \\
\hline 5 & $7.025,7.725$ & Histidine & $*(\uparrow)$ & $*(\uparrow \uparrow)$ & $*(\uparrow \uparrow \uparrow)$ \\
\hline 6 & 7.405 & Phenylalanine & $*(\uparrow)$ & $(\downarrow \downarrow) \#$ & $*(\downarrow \downarrow)$ \\
\hline 7 & 1.455 & Alanine & $*(\downarrow)$ & $(\downarrow \downarrow) \#$ & $*(\downarrow \downarrow)$ \\
\hline 8 & $1.695-1.715$ & Arginine & $*(\uparrow)$ & $(\downarrow \downarrow) \#$ & $(\downarrow \downarrow) \#$ \\
\hline 9 & 2.435 & Glutamine & $*(\downarrow)$ & $*(\downarrow \downarrow \downarrow)$ & $*(\downarrow \downarrow)$ \\
\hline 10 & 1.995 & Proline & $*(\downarrow)$ & $(\uparrow)$ & $*(\downarrow \downarrow \downarrow)$ \\
\hline 11 & 3.535 & Glycine & $*(\uparrow)$ & $*(\uparrow)$ & $*(\uparrow)$ \\
\hline 12 & $6.885,7.175$ & Tyrosine & (个)\# & $*(\downarrow \downarrow \downarrow)$ & $*(\downarrow \downarrow)$ \\
\hline 13 & $1.865-1.885$ & Citrulline & $*(\uparrow)$ & $(\uparrow \uparrow) \#$ & $(\uparrow \uparrow \uparrow) \#$ \\
\hline 14 & 3.015 & Creatine & $(\uparrow)$ & $*(\downarrow \downarrow)$ & $*(\downarrow \downarrow)$ \\
\hline 15 & 1.895 & Acetate & $(\uparrow) \#$ & $*(\downarrow \downarrow)$ & $*(\downarrow \downarrow \downarrow)$ \\
\hline 16 & 2.025 & NAG & $(\uparrow)$ & $*(\downarrow \downarrow \downarrow)$ & $*(\downarrow \downarrow)$ \\
\hline 17 & $2.115,2.125$ & OAG & (个)\# & $*(\downarrow \downarrow)$ & $*(\downarrow \downarrow)$ \\
\hline 18 & 2.325 & Glutamate & $*(\downarrow)$ & $*(\downarrow \downarrow \downarrow)$ & $*(\downarrow \downarrow)$ \\
\hline 19 & $3.885,5.215$ & Glucose & $*(\downarrow)$ & $*(\downarrow)$ & $*(\downarrow)$ \\
\hline 20 & 3.605 & Myo-Inositol & $*(\uparrow)$ & $(\downarrow \downarrow) \#$ & $(\downarrow \downarrow \downarrow)$ \\
\hline 21 & 1.315 & Lactate & $(\uparrow)$ & $*(\downarrow \downarrow)$ & $*(\downarrow \downarrow)$ \\
\hline 22 & 3.185 & Choline & $*(\downarrow)$ & $(\downarrow \downarrow) \#$ & $*(\downarrow \downarrow)$ \\
\hline 23 & 5.365 & Allantoin & $*(\uparrow)$ & $(\uparrow) \#$ & $*(\uparrow)$ \\
\hline 24 & 8.435 & Formate & $*(\uparrow)$ & $*(\uparrow \uparrow)$ & $(\uparrow \uparrow \uparrow \uparrow) \#$ \\
\hline 25 & $8.825,9.115$ & Trigonelline & $*(\uparrow)$ & $(\uparrow \uparrow \uparrow) \#$ & $(\uparrow \uparrow) \#$ \\
\hline
\end{tabular}

The up and down arrows represent, respectively, increased and decreased metabolite levels. A $\uparrow \uparrow \uparrow / \downarrow \downarrow \downarrow$ or $\uparrow \uparrow / \downarrow \downarrow$ score was given to the metabolites of the treatment dose which showed ameliorating effects from DMBA towards control. Abbreviations used are as follows: LDL (low density lipoproteins); VLDL (very low density lipoproteins); NAG (N-acetyl glycoprotein); OAG (O-acetyl glycoprotein); PUFA (poly unsaturated fatty acids).

Note-: Symbols * = p-value $<0.05$, \# = VIP Score $<1$.

immunoblotting assay were endorsed by the qRT-PCR studies, embarking that the effect of ALA is mediated through regulating the respective genetic phenotypes. The qRT-PCR studies for the hypoxic markers recorded similar pattern of fold changes as perceived through the immunoblotting assay (Figure 12).

\section{DISCUSSION}

The in-vitro studies affirmed significant cytotoxic and apoptotic potential of ALA against ER+ MCF-7 cells, when scrutinized through MTT assay (Figure 1) and AO/
EtBr staining. The ALA treated $\mathrm{AO} / \mathrm{EtBr}$ stained cells were evident for the presence of apoptosis as visualized with nuclear shrinkage, chromatin condensation, fragmented nuclei, and membrane blebbing [11] (Figure 2). Considering the fact that mitochondria participates in apoptosis, the effect of ALA on mitochondrial membrane potential was validated through cationic dye JC-1. Greater membrane potential results in higher accumulation of JC-1 and formation of J-aggregates, which exhibit maximal fluorescence emission at $\sim 590$ $\mathrm{nm}$ (red)[12]. Loss in mitochondrial membrane potential results in failure to accumulate J-aggregate and their 

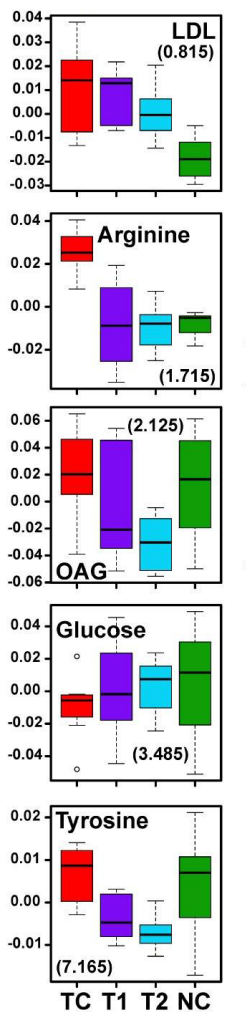
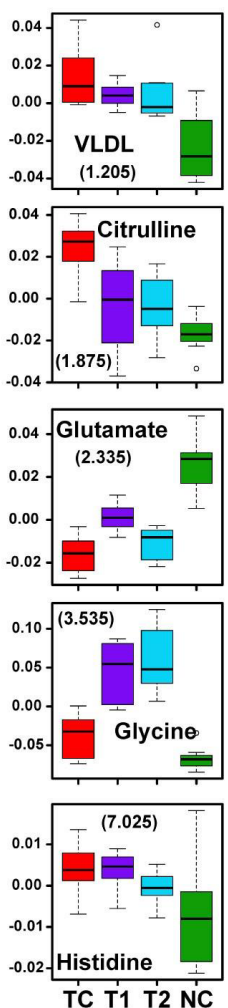

DMBA

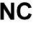

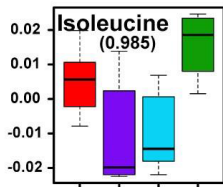
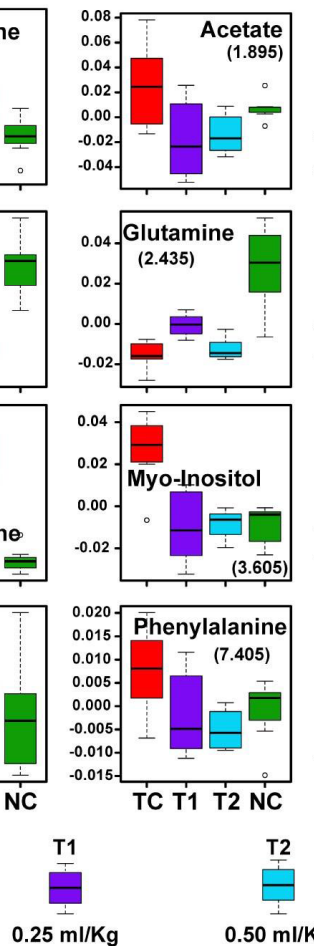
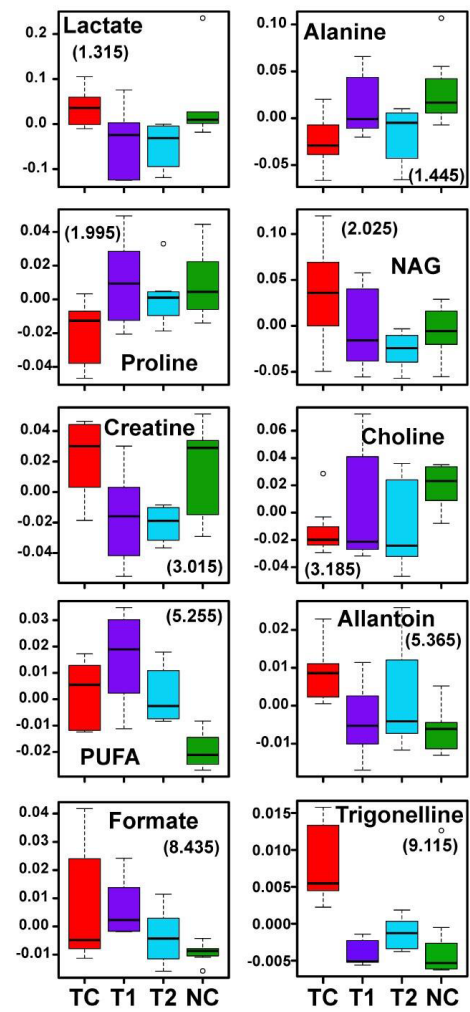

NC

Control

Figure 9: Biochemical effects of ALA treatment. Representative box-cum-whisker plots showing quantitative variations of relative signal integrals for serum metabolites relevant in the context of pathophysiology of mammary gland cancer. For presented metabolite entities, the VIP score $>1$ and statistical significance is at the level of $p \leq 0.05$. In the box plots, the boxes denote interquartile ranges, horizontal line inside the box denote the median, and bottom and top boundaries of boxes are $25^{\text {th }}$ and $75^{\text {th }}$ percentiles, respectively. Lower and upper whiskers are $5^{\text {th }}$ and $95^{\text {th }}$ percentiles, respectively.

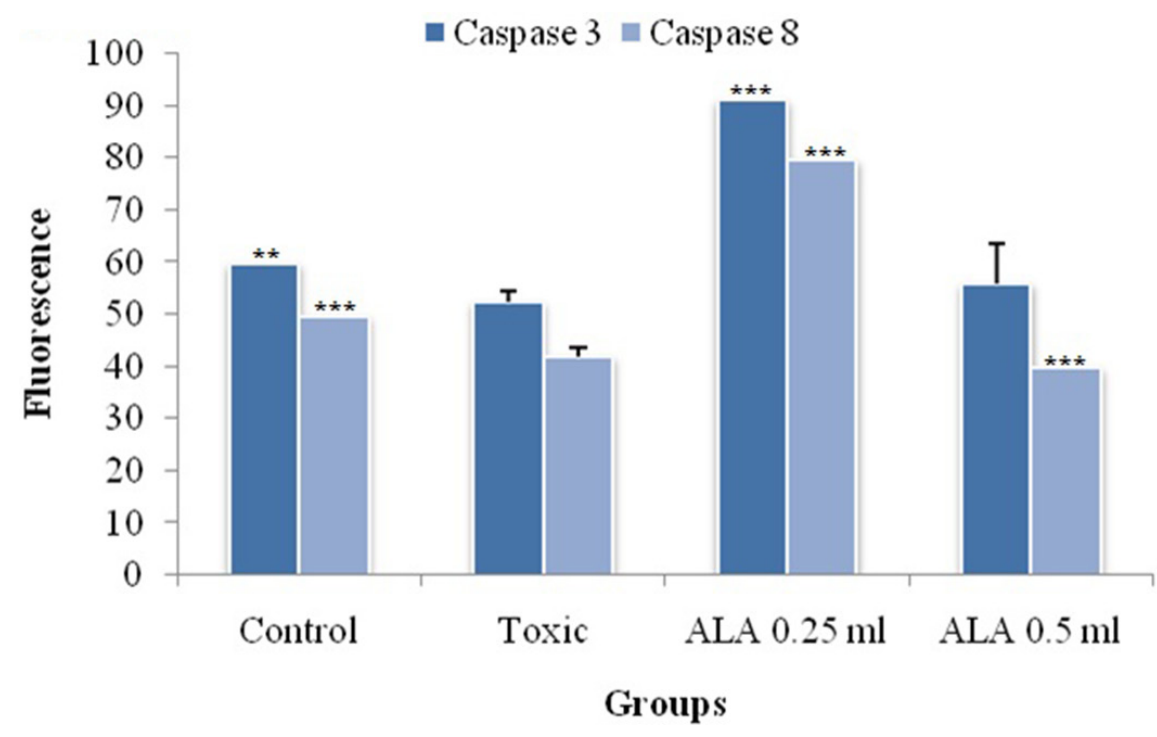

Figure 10: Effect of ALA on caspase3 and caspase8. The activity of caspase was detected by commercial fluorescence based assay. Data are expressed as mean+ SD of individual groups. Comparisons are made by the one-way ANOVA followed by Bonferroni multiple test. All groups are compared to the DMBA treated group $(* \mathrm{p}<0.05, * * \mathrm{p}<0.01, * * * \mathrm{p}<0.001)$. 
existence in the monomeric form, which exhibit green fluorescence. Therefore, JC-1 is considered to be an indicator of mitochondrial potential and decrease in mitochondrial membrane potential is an indicative of apoptosis as perceived after the ALA treatment (Figure 3). Subsequent studies affirmed the cell cycle arrest in G2/M phase by the ALA treatment (Figure 4). Translocation of phosphatidylserine (PS) to the outer leaflet of the cellular membrane is a key marker of apoptosis and could be validated through Annexin-V, (calcium-dependent phospholipid binding protein) labeled with FITC and PI [13]. The same revealed, ALA mediated apoptosis to be associated with PS translocation (Figure 5). All in all, invitro studies affirmed participation of two major hallmarks of apoptosis, including changes in mitochondrial permeability and PS translocation after the ALA treatment in a dose dependent manner.

As encouraged through in-vitro studies, the efficacy of ALA was further validated in-vivo against
DMBA induced mammary gland carcinoma. DMBA is a polycyclic aromatic hydrocarbon and is used to induce mammary gland carcinoma in experimental animals. The mammary tumors produced from DMBA are morphologically and histopathologically very similar to human tumors [14]. DMBA is an indirect carcinogen, and requires metabolic activation by cytochrome $\mathrm{P} 450$ enzymes to reactive metabolites, i.e. dihydrodiolepoxides and forms mutagenic DNA adduct [15]. Mainly two enzymes viz cytochrome P4501B1 (CYP1B1) and microsomal epoxide hydrolase (EPHX1) are responsible for DMBA bioactivation [16].

Autonomic dysfunction associated with cardiovascular complications, poor quality of life and premature mortality are well reported phenomenon in the breast cancer survivors [17]. Infact, autonomic dysfunction is now a day is considered as a non-invasive prognostic marker for chemotherapeutic regime [18]. $\mathrm{HRV}$ is a clinical marker of autonomic function and
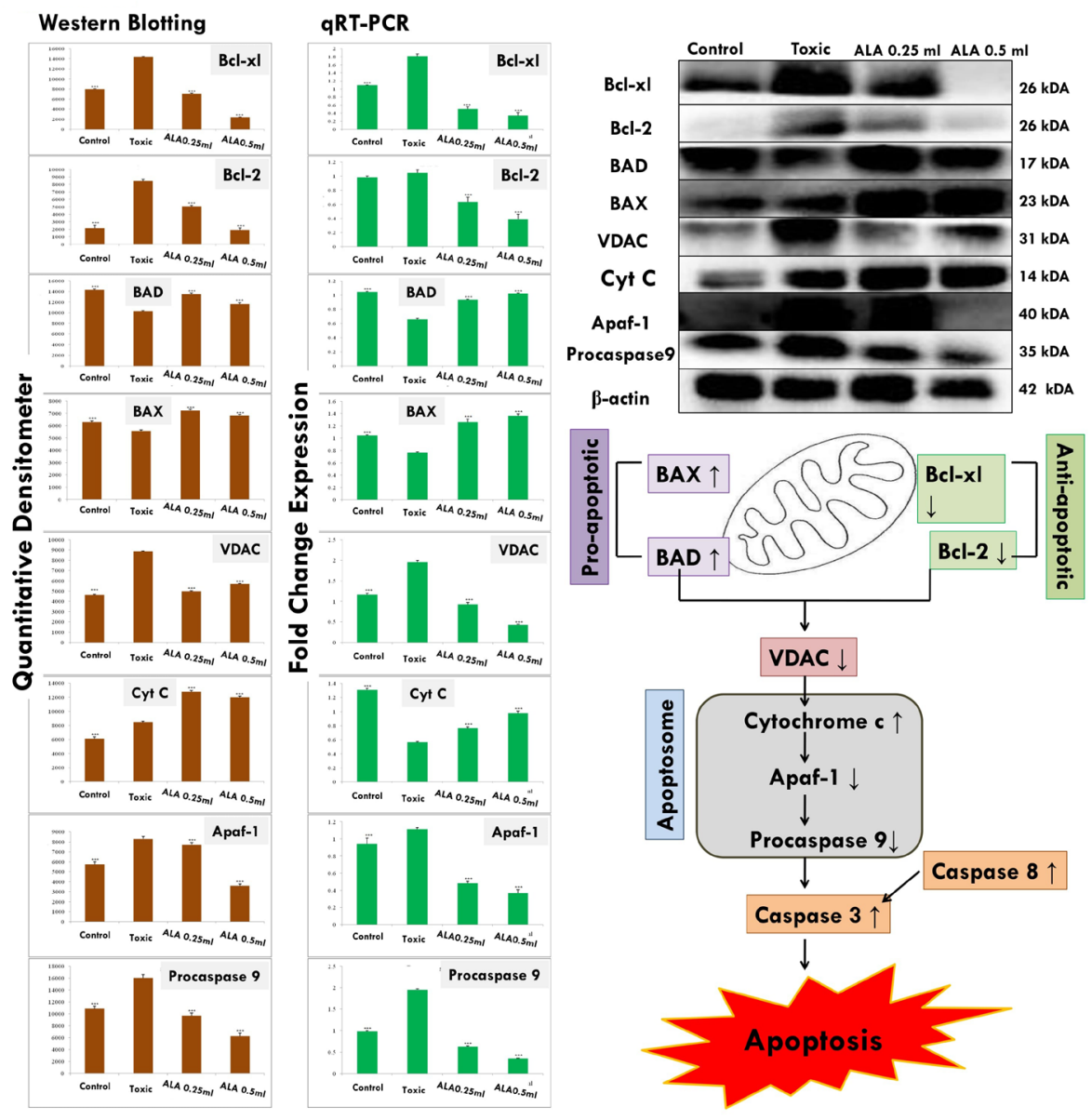

Figure 11: ALA mediated activation of mitochondrial associated protein signaling in mammary gland cells. Protein extracted from individual groups [1-control, 2-DMBA treated, 3-ALA (0.25 ml/kg, p.o. + DMBA $8 \mathrm{mg} / \mathrm{kg}$, i.v.) and 4- ALA (0.5 ml/ $\mathrm{kg}$, p.o. + DMBA $8 \mathrm{mg} / \mathrm{kg}$, i.v.)] were subjected to immunoblotting of proapoptotic (BAX) and anti-apoptotic (Bcl-2 and Bcl-xl) protein with downstream apoptotic markers (VDAC, cytochrome-c, Apaf-1and procaspase9) of respective pathway. mRNA expression of above mentioned protein were also in line with the findings of immunoblotting assay. $\beta$-actin was used as loading control. Each experiment was performed in triplicate. Values are presented as mean $\pm \mathrm{SD}$. Comparisons are made by the one-way ANOVA followed by Bonferroni multiple test. All groups are compared to the DMBA treated group $\left(* \mathrm{p}<0.05,{ }^{* *} \mathrm{p}<0.01,{ }^{* * *} \mathrm{p}<0.001\right)$. 
cancer patients with low HRV are associated with increased cardiovascular risk [19]. Treatment with ALA helped to restore the autonomic control and therefore, could be designated to have good prognostic value in chemoprevention regime as proposed through ALA (Table 1, Supplementary Table 1 and Supplementary Figure 1). It would be appropriate to put on records, that low dose of ALA imparted more favorable regulation of ECG and HRV paradigms in comparison to high dose of ALA. Interestingly, high dose of ALA further deteriorates time and frequency domain parameters of HRV. Authors would also like to submit that a meta-analysis concluded that short term PUFA's supplementation may favorably influence HRV parameters as observed through low dose of ALA in the present study [20].

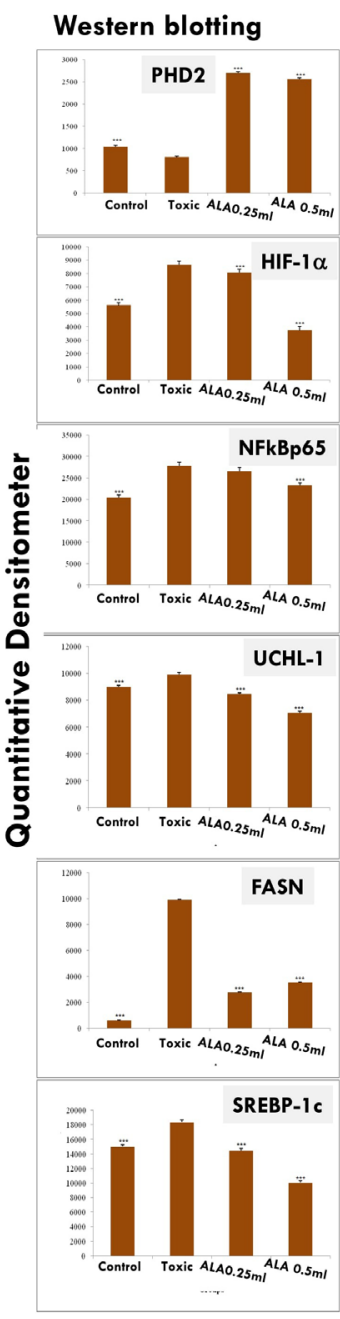

Cellular proliferation and angiogenesis are welldefined hallmarks for cancer progression [21]. As an advantage of in-vivo studies, same could be studied through carmine staining, H\&E staining and SEM. The carmine staining was evident for the development of proliferative lesions as represented by increase in $\mathrm{AB}$ in DMBA treatment. The $\mathrm{AB}$ represents the largest bulbous structure located at the distal end of the mammary epithelial tree and is the site for the malignant transformation [22]. The DMBA treatment was evident for increase in $\mathrm{AB}$, which is in corroboration with a previous study [23] (Figure 6A-6D). Treatment with DMBA was also evident for the scattered pattern of CEC, hardly located LCT and DCT along with loss of duct and MEC, as visualized by $\mathrm{H} \& \mathrm{E}$ staining (Figure 6E-6H). Marked

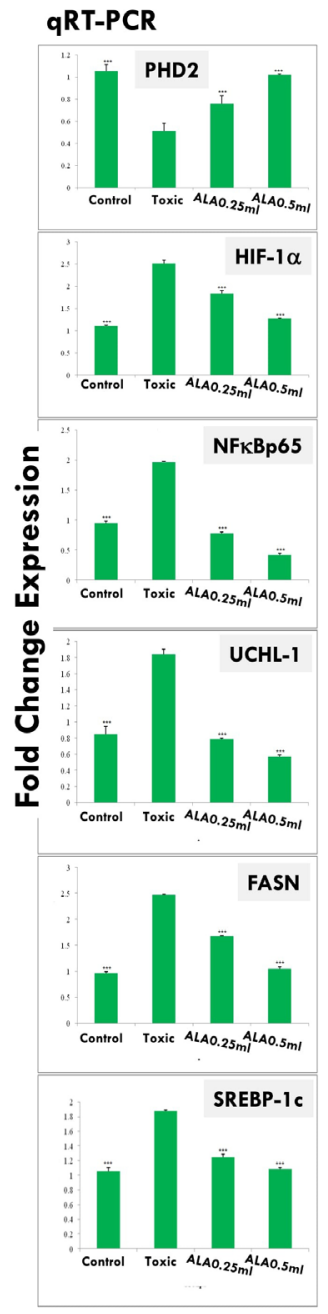

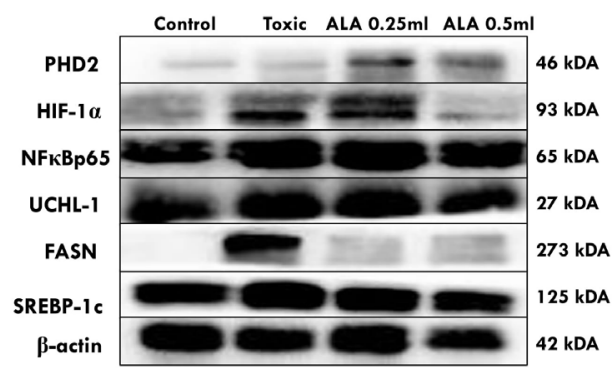
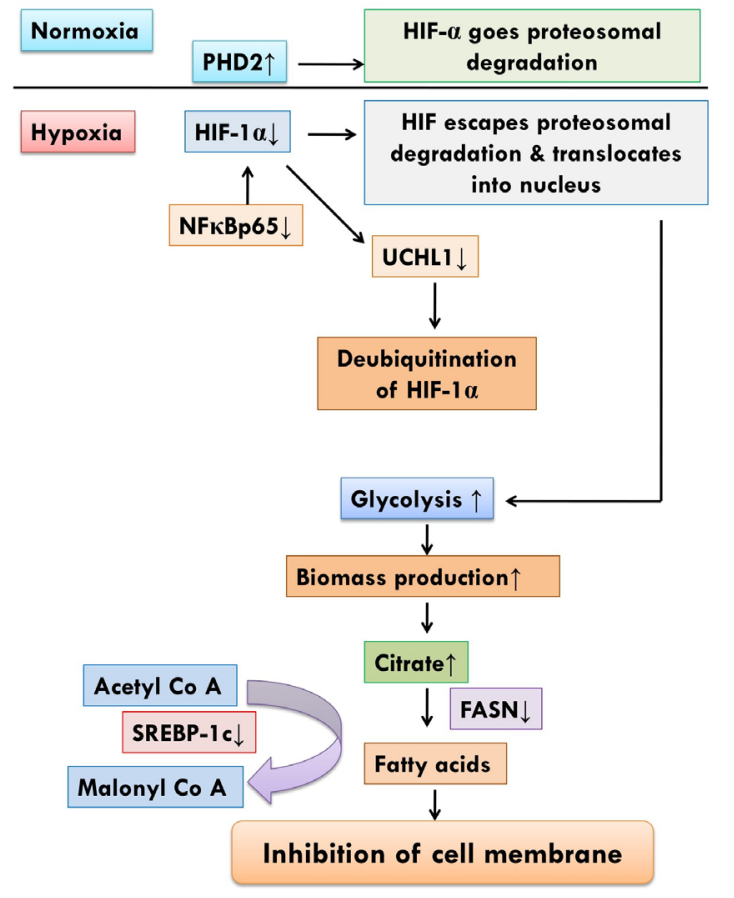

Figure 12: Effect of ALA on HIF-1a mediated hypoxic markers and fatty acid synthesis regulators. Immunoblotting of respective individual group [1-control, 2-DMBA treated, 3-ALA $(0.25 \mathrm{ml} / \mathrm{kg}$, p.o. + DMBA $8 \mathrm{mg} / \mathrm{kg}$, i.v. $)$ and 4- ALA (0.5 ml $/ \mathrm{kg}$, p.o. + DMBA $8 \mathrm{mg} / \mathrm{kg}$, i.v.)] for HIF-1 $\alpha$, PHD2, and FASN conclude the hypoxic microenvironment after DMBA treatment. Perspective correlations of NFKBp65, UCHL-1 and SREBP-1c with the above mentioned protein are well defined through the experimental pathway. Excised mammary gland tissue sample lysed in trizol for RNA extraction and analyzed for the mRNA expression of HIF-1 $\alpha$, PHD2, FASN, NFאBp65, UCHL-1 and SREBP-1c by qRT-PCR: fold induction is relative to tissue under hypoxic conditions after normalization to the $\beta$-actin expression. Each experiment was performed in triplicate. Values are presented as mean $\pm \mathrm{SD}$. Comparisons are made on the basis of the one-way ANOVA followed by Bonferroni multiple test. All groups are compared to the DMBA treated group $\left({ }^{*} \mathrm{p}<0.05,{ }^{*} \mathrm{p}<0.01\right.$, $* * * \mathrm{p}<0.001)$. 
cellular proliferation after the DMBA treatment was also evident for increase in micro vessel formation, loss of intra-arterial cushion and vascular conglomeration when perceived through SEM analysis (Figure 6I-6L). It would be appropriate to remark, that findings derived from the carmine staining, H\&E staining and SEM analysis are well in line with previous reports [24, 25]. Treatment with ALA demarcated a marked impression on cellular architecture and morphology, as evident through decrease in $\mathrm{AB}$, restoration of the cellular architecture, decrease in micro vessel formation with profound impression on the branching sites. Enlarged capillaries, which are the sign of rapidly growing tumors were also absent in ALA treated groups. All in all, ALA imparted a significant doseindependent effect to curtail cellular proliferation and therefore, warrant's further validation through biochemical and molecular biology markers.

The biochemical markers could be majorly categorized as the ones associated with antioxidant defense or to the physiological mechanisms, and authors validated both. Reactive oxygen species (ROS) are constantly produced in all aerobic cells and are counter balanced by the antioxidant enzymatic defense [26]. However, during anaerobic/hypoxic conditions like cancer (due to increased cellular proliferation), the counter balance effects of antioxidant enzymes are subsided [27]. The damage to the cellular lipids and proteins can be validated through increased production of TBARs and PC respectively; which was very well evident after the DMBA treatment. The increased ROS production also inhibits the enzymatic antioxidant defense of GSH, SOD and catalase, as they all work in tandem to curtail ROS through series of peroxidation, dismutation and oxidation reactions [28]. The decrease in the enzymatic defense of SOD, catalase and GSH, suggest their increased utilization, which was profoundly evident after the DMBA treatment. It would be appropriate to remark that ALA administration curtailed the levels of TBARs and PC with restoration of enzymatic antioxidant defense of SOD, catalase and GSH (Table 2). In contradiction to the findings in the preceding paragraphs, ALA high dose was observed to be more efficacious in comparison to low dose and the same could be attributed to the fact that ALA being a PUFA would have rendered himself against the ROS (in lieu of cellular lipids) and acted as a pro-oxidant (dose dependently) rather than anti-oxidant as elaborated by our laboratory in a previous report [29].

The DMBA induced changes indicated that subsets of metabolites were changed in similar way in all groups, which were ameliorated by ALA treatment. The decreased glucose and increased lactate and myoinositol levels in DMBA are well correlated with warburg effect and increased bioenergetics demand for cellular proliferation [30] (increased glycolytic activity with increased lactate production)[31]. Further, significant increase in the levels of lipoproteins (LDL/VLDL) and
PUFAs, in DMBA treated animals suggests increased requirement of the building blocks of the cell membranes in rapidly proliferating tumor cells [32]. Exogenous ALA supplementation provided further increase in the levels of lipoproteins (LDL/VLDL) and PUFA's and the same could be attributed to the fact that ALA is a polyunsaturated fat. The lower levels for choline could be the consequence of excessive need for choline and its derivatives during rapid cell proliferation $[33,34]$.

Inflammation is a most common clinical manifestation of various cancer types and triggers a hypercatabolic state, resulting in increased energy requirements. Consistent with this phenomenon the increased concentrations of serum acetyl-glycoproteins (both NAG and OAG) (acute phase anti-inflammatory proteins expressed during inflammation and immune response) was recorded after the DMBA treatment and is in line with previous investigations in liver disease, inflammatory disease, and cancer [35-37]. As expected, ALA (an antiinflammatory PUFA) curtailed the expression of acute phase proteins expressed during inflammation [38].

The increased levels of amino acids like arginine, glycine, histidine, tyrosine, creatine and phenylalanine indicate abnormal/aberrant biosynthesis of amino acids in DMBA treated rats. The increased levels of arginine and citrulline suggest protein catabolism, deriving overall picture of high metabolic activity, a hallmark for tumor progression [39],[40],[41]. The high metabolic activity as evident through increased levels of amino acids was also endorsed through increased levels of formate (a product of glycine metabolism through glycine succinate pathway) [42]. The decreased level of glucogenic amino acids (glutamate, glutamine, proline, isoleucine and alanine) in DMBA treated group suggests their increased utilization in energy production. Proline metabolism is especially important in nutrient stress, as it is interchangeably converted into glutamate and glutamine. Concomitant ALA treatment further diminished the levels of glucogenic amines which could be accounted to the fact that exogenous ALA would have provided a faulty lipid to the fastly growing tumour cells. Whereas the requirement for the amino acids as a building block for cellular membranes was prevalent till such time.

The deregulated metabolites represent altered cancer cell energy metabolism including amino acid metabolism (glutamate, glutamine, alanine, etc.), glycolysis or gluconeogenesis (glucose, and lactate,) and lipid metabolism (LDL, VLDL, choline, and acetate) and are associated with high rate of glycolysis. Most of the metabolic changes in DMBA treated animals were reset back to normal after ALA administration, suggesting that the ALA has potential to balance the metabolic abnormalities in fastly growing cells (Figure 9).

The findings from the antecedent sections are clear indicative that ALA has a definite say towards mitochondrial energy production, glycolysis and fatty acid 
synthesis to fuel the high energy and biomass demands for the tumor growth. Given the same, we considered it worth to validate the molecular biology markers for mitochondrial apoptosis and fatty acid synthesis.

The mitochondrial apoptosis is governed through series of pro-apoptotic and anti-apoptotic regulators [43]. The ALA decreased the expression of anti-apoptotic (Bcl-2 and Bcl-xl) along with increase in pro-apoptotic (BAX and BAD) markers. The mitochondrial apoptotic changes are further associated with decreased expression of VDAC, due to loss in the channel integrity with concomitant release of cytochrome c $[44,45]$. The immunoblotting and qRT-PCR studies affirmed the decreased expression of VDAC with concomitant increase in cytochrome c expression after the ALA treatment. Once released from mitochondria, cytochrome c binds with Apaf-1 and procaspase 9 to form adduct termed, apoptosome [46]. Apoptosome formation accounts for the decreased cytosolic levels of Apaf-1 and procaspase 9 and the same was evident after the ALA treatment [47]. Apoptosome formation further cleaves the procaspase 9 to give active caspase 9 which is involved in the intrinsic apoptotic pathway and mediate the activation of effecter caspase 3 and 8 for execution of apoptosis [48]. Treatment with ALA (low dose) increased the level of caspase 3 and 8 and thereby accredited apoptosis. It would be appropriate to pendown that ALA (high dose) was not as effective as low dose, which is not in line with the findings reported in preceding paragraphs. However, authors are opined that such observation could be the consequence of feedback inhibition of caspase 3 and 8 [49]. Similar type of findings with other PUFA's, particularly DHA has been reported previously [50, 51]. From the above line of evidences, authors could easily derive that the proliferative and angiogenic effects of DMBA are curtailed by ALA through activating the mitochondrial-mediated apoptosis death pathway (Figures 10 and 11).

Rapidly growing tumor cells derive energy majorly through glycolysis due to insufficient oxygen (hypoxia) [52]. The hypoxia in the cellular microenvironment is controlled with the help of hypoxia inducible factor$1 \alpha$ (HIF-1 $\alpha)$, which is further synchronized through oxoglutarate dependent hydroxylase called prolyl hydroxylase -2 (PHD2)[53]. Increased glycolytic activity in the rapidly proliferating cells is coupled with increased FASN to meet the fatty acid requirements through de novo synthesis [54]. ALA treatment increased the PHD2 expression and curtailed the HIF- $1 \alpha$ expression, once validated through immunoblotting and qRT-PCR assay. The curtailment of HIF-1 $\alpha$ was also validated through reduced expression for $\mathrm{NF} \kappa \mathrm{Bp} 65$ and UCHL-1, as NFкBp65 impart positive modulatory effect upon HIF$1 \alpha$ and UCHL- 1 felicitates the deubiquination of HIF$1 \alpha$ (HIF-1 $\alpha$ to escape proteasomal degradation during hypoxia through deubiquination) $[55,56]$. ALA treatment decreased the FASN expression at protein and mRNA level, suggesting decreased de novo synthesis of fatty acids (Figure 12). Decreased fatty acid synthesis was further endorsed through abated expression for SREBP1c, a regulator for conversion of acetyl CoA to malonyl CoA during de novo fatty acid synthesis $[57,58]$.

Supplementation with $\omega-3$ PUFA can impart favorable modification of membrane fatty acid composition or detrimental oxidative metabolism within the cell. Low dose of $\omega-3$ PUFA has been reported not to induce harmful modifications of oxidative cell metabolism, as modifications of membrane fatty acid composition occur $[59,60]$. The reports also suggest the possibility for use/better efficacy of low doses of $\omega-3$ PUFA for chemoprevention and same was observed after the ALA treatment $[61,62]$. On the whole, ALA curtailed the hypoxic microenvironment, de novo fatty acid synthesis and arbitrated mitochondrial mediated apoptosis to restrain proliferative and angiogenic effects of DMBA.

\section{MATERIALS AND METHODS}

\section{Drugs and chemicals}

ALA (463-40-1) $(0.914 \mathrm{gm} / \mathrm{ml})$ was purchased from TCI Chemicals (India) Pvt. Ltd. RPMI 1640 (Gibco, USA); fetal bovine serum (FBS) (Gibco-10270); trypsin (Gibco, USA); eagle balanced salt solution (EBSS)(Gibco, 2018-11); hank's balanced salt solution (HBSS) (Himedia, TL1190); EtBr (Himedia, MB071); AO(Himedia, MB116); JC-1 assay kit (Thermo Scientific, M34152); PI (SC-3541); tamoxifen citrate (TMX) (Tammodex 20, Biochem Pharmaceuticals India); penicillin- streptomycin (Thermo Scientific, 15410163); gentamycin (Thermo Scientific, 15710-049);3-(4, 5-Dimethyl-2-thiazolyl)-2, 5-diphenyl-2H-tetrazolium bromide (MTT) (Himedia, TC191); RNase (SRL, 58895); dimethyl sulfoxide (DMSO) (Merck, 1.16743.0521); DMBA (Sigma Aldrich, 57-97-6); ponceau S (Himedia, ML045); sodium cacodylate (Sigma Aldrich, C0250); collagenase type 4 (Himedia, TC-214); hyaluronidase (Himedia, TC331); hematoxylin (Himedia, S058); eosin (Himedia, S007); RIPA lysis buffer (Amresco, N653); protein assay kit (Amresco, M173); bovine serum albumin (BSA) (Genetix, PG-2330); transfer buffer (Genetix, GX9411AR), trizol reagent (Sigma-T9424), cDNA synthesis kit (Genetix-K1612). Caspase 3 (SC-4263) and caspase 8 (SC-4267) assay kits were procured from Santacruz Biotechnology Inc., California, Delaware. All others chemicals were of molecular biology grade and purchased from Genetix Biotech Asia Pvt. Ltd, New Delhi.

\section{Cell line and culture condition}

The ER+MCF-7cells were cultured and routinely maintained in RPMI 1640 medium supplemented with $10 \%$ heat inactivated FBS, penicillin (100 units $/ \mathrm{ml}$ ), 
streptomycin $(100 \mu \mathrm{g} / \mathrm{ml})$ and gentamycin $(100 \mu \mathrm{g} / \mathrm{ml})$ in a humidified atmosphere at $37^{\circ} \mathrm{C}$ containing $5 \% \mathrm{CO}_{2}$ inside a $\mathrm{CO}_{2}$ incubator [63].

\section{Cytotoxicity study with MTT}

Cytotoxicity was measured by using MTT assay. ER+MCF-7 cell lines $\left(1 \times 10^{5}\right)$ were seeded in 96 well sterile plates and were treated with different concentrations of ALA $(1 \mu \mathrm{M}, 5 \mu \mathrm{M}, 10 \mu \mathrm{M}, 15 \mu \mathrm{M}, 20 \mu \mathrm{M}, 25 \mu \mathrm{M})$ for $24 \mathrm{~h}$, compared against control and standard (TMX) $(27 \mu \mathrm{M})$. Subsequently media form upper layer was removed and incubate with $20 \mu \mathrm{l}$ MTT $(5 \mathrm{mg} / \mathrm{ml})$ and $100 \mu \mathrm{l}$ of fresh media for $2 \mathrm{~h}$. Blue colored formazans were released from the cells by adding $100 \mu \mathrm{LMSO}$ with gentle shaking at $37^{\circ} \mathrm{C}$. After $30 \mathrm{~min}$ incubation the absorbance of the color solution was quantified by measuring at a wavelength of $570 \mathrm{~nm}$ by micro plate reader (Model 680 XR Bio-Rad laboratories $\operatorname{lnc}$ ). $\mathrm{IC}_{50}$ value and $1 / 2 \mathrm{IC}_{50}$ value of ALA against ER+MCF-7 cells were determined after $24 \mathrm{~h}$ [64].

\section{Detection of apoptosis through $\mathrm{AO} / \mathrm{EtBr}$ staining}

Characteristic apoptotic morphological changes were observed by inverted fluorescence microscopy by using $\mathrm{AO} / \mathrm{EtBr}$ staining. ER+MCF-7 cells $\left(1 \times 10^{6}\right)$ were treated with $1 / 2$ IC 50 and IC50 dose of ALA and TMX for $18 \mathrm{~h}$, and were observed under the inverted fluorescence microscope for morphological changes. The untreated control cells and ALA treated cells were harvested separately, washed with PBS and stained with $\mathrm{AO}(100 \mu \mathrm{g} / \mathrm{ml})$ and $\mathrm{EtBr}(100 \mu \mathrm{g} / \mathrm{ml})(1: 1)$. The cells were immediately mounted on slides and visualized under an inverted fluorescence microscope (Nikon Leica, M165 FC) for the changes in morphological features of apoptosis [65].

\section{Identification of mitochondrial morphology through JC-1 dye}

Alteration in the $\Delta \Psi \mathrm{m}$ was analyzed by inverted fluorescence microscope using the mitochondrial membrane potential sensitive dye JC-1. JC- 1 forms J-aggregate in control cells in intact mitochondrial membrane potential. Stock solution of $1 \mathrm{mg} / \mathrm{ml} \mathrm{JC}-1$ was prepared in $1 \% \mathrm{DMSO}$ and stored at $-20^{\circ} \mathrm{C}$ shortly before use. After incubation for $24 \mathrm{~h}$ with $1 / 2$ IC 50 and IC 50 dose of ALA, cells were washed three times with PBS and $200 \mu \mathrm{l}$ of JC- $1(1 \mathrm{mg} / \mathrm{ml})$ dye was added into each well. After incubation for $20 \mathrm{~min}$, cells were washed three times with PBS and imaged with an inverted fluorescence microscope (Nikon Leica, M165 FC)[66].

\section{Cell cycle analysis using PI}

The cells were treated with a fluorescent dye PI that quantitatively stains DNA. The amount of DNA was measured by the fluorescence intensity of the stained cells. For the investigation of cell cycle arrest stage, $1 \times 10^{6}$ cells were treated with IC 50 and $1 / 2$ IC 50 of ALA for $18 \mathrm{~h}$. Cells were washed with PBS, fixed with methanol and kept at $-20{ }^{\circ} \mathrm{C}$ for $3 \mathrm{~min}$. Subsequently, cells were suspended in cold PBS and kept at $4{ }^{\circ} \mathrm{C}$ for $90 \mathrm{~min}$. Cells were pelleted down, dissolved in PBS, treated with RNase for $30 \mathrm{~min}$ at $37^{\circ} \mathrm{C}$, stained with PI and kept in dark for 15 min. Cell cycle phase distribution of nuclear DNA was determined on florescence activated cell sorter (FACS), fluorescence detector equipped with $488 \mathrm{~nm}$ argon laser light source and $623 \mathrm{~nm}$ band pass filter (linear scale) using BD FACS software 1.2.0.87 (BD Influx cell sorter, USA)[63].

\section{Annexin-V FITC dot plot assay}

Annexin-V FITC is a $35-36 \mathrm{kDa} \mathrm{Ca}{ }^{2+}$ dependent phospholipid-binding protein, which has high affinity for PS, and it binds to the exposed cell surface of apoptotic cell. The ER+MCF-7 cells $\left(1 \mathrm{X} 10^{6}\right)$ were treated with individual IC50 and $1 / 2$ IC 50 dose of ALA for $18 \mathrm{~h}$. The cells were pellet down, centrifuged at $2000 \mathrm{rpm}$ for $8 \mathrm{~min}$ at $4{ }^{\circ} \mathrm{C}$ and washed with annexin-V FITC binding buffer provided in apoptosis kit. After centrifugation at $2000 \mathrm{rpm}$ at $4{ }^{\circ} \mathrm{C}$, the cell pellets were dissolved in annexin-V FITC binding buffer containing annexin-V FITC and PI. The flow cytometric analysis was done after $15 \mathrm{~min}$ in dark at room temperature. All the data were acquired with a BD Influx cell sorter, USA. The reading were taken by using $488 \mathrm{~nm}$ excitation and band pass filters of 530/30 nm (for FITC detection) and 585/42 nm (for PI detection). For the alignment of $\mathrm{X}$ and $\mathrm{Y}$ mean values of annexin-V FITC or PI stained quadrant populations, live statistics were used. Data analysis was performed with BD FACS software 1.2.0.87 [67].

\section{Experimental protocol}

Thirty two female albino wistar rats were randomized and divided into four groups of eight animals each. Animals were housed in standard condition $\left(23^{\circ} \mathrm{C}, 12 \mathrm{~h}\right.$ light/dark cycle). The rats were obtained from central animal house facility of Babu Banarsi Das Northern India Institute of Technology, Lucknow and were housed in polypropylene cages. The animals were fed with standard pellet diet and water ad libitum. The experiment was performed according to the CPCSEA guidelines for laboratory animals and ethics, Department of animal welfare, Government of India (BBDNIIT/ IAEC $/ 021 / 2014)$. The animals were subjected to the treatment as Group I (control, normal saline, $1 \mathrm{ml} / \mathrm{kg}$, p.o.), Group II (toxic, DMBA $8 \mathrm{mg} / \mathrm{kg}$, i.v.), Group III (DMBA $8 \mathrm{mg} / \mathrm{kg}$, i.v. + ALA $0.25 \mathrm{ml} / \mathrm{kg}$, p.o.) and Group IV (DMBA $8 \mathrm{mg} / \mathrm{kg}$, i.v. + ALA $0.5 \mathrm{ml} / \mathrm{kg}$, p.o.). Toxicity was induced by single tail vein injection of DMBA on 
day 1 . ALA was administered from $7^{\text {th }}$ to $110^{\text {th }}$ day at the dose specified above. The dose of ALA was selected from previous literature [68]. Tumors incidence and size were measured by the help of vernier caliper (Supplementary Table 2). Animals were sacrificed by cervical dislocation under light ether anesthesia on $112^{\text {th }}$ day.

\section{Hemodynamic changes}

The animals were anesthetized on $111^{\text {th }}$ day of the study by using the combination of ketamine hydrochloride (50 mg/kg, i.m.) and diazepam (2.5 mg/kg, i.m.) and mounted on a wax tray. The platinum hook electrodes were placed on the skin of the dorsal and ventral thorax to record the ECG signal. The electrodes were connected to Bio-amplifier (ML-136) and channel power lab (ML-826) to convert analogue to digital signals (AD Instruments, Australia). The ECG signals were saved on the hard disk and analyzed offline using Lab Chart Pro-8 (AD Instruments, Australia)[69].

HRV analysis was conducted on multiple segments of continuous ECG signals. Firstly, all the raw signals were inspected manually to ensure that all the R-waves were detected correctly. Subsequently, HR was calculated by plotting the number of $\mathrm{R}$ waves per unit time. Following the same, time and frequency domain parameters of HRV were also calculated using Lab Chart Pro-8 (AD Instruments, Australia)[70].

\section{Morphological evaluation}

\section{Carmine staining of whole mounts mammary gland}

The mammary glands obtained from female albino wistar rats were stretched onto a slide and kept in a fixative solution (60:30:10 ratio of ethanol: chloroform: acetic acid), stained with a carmine solution for 2 days, washed with $90 \%, 70 \%, 35 \%$ and $15 \%$ ethyl alcohol for $1 \mathrm{~h}$ respectively and lastly rinsed with distilled water for three times at 5 min interval. The tissue sample was dehydrated in ascending grades of alcohol and dipped in xylene at least for two days. Carmine alum stain was prepared with $1 \mathrm{gm}$ carmine and $2.5 \mathrm{gm}$ aluminum potassium sulfate in $450 \mathrm{ml}$ distilled water and boiled for $20 \mathrm{~min}$. The final volume was adjusted to $500 \mathrm{ml}$ with distilled water. Whole mounts were examined under the $4 \mathrm{X}$ microscope and evaluated for ABs [24, 71].

\section{Histopathology of mammary gland tissue}

A small piece of mammary gland tissue was fixed in $10 \%$ solution of formaldehyde and embedded in the wax. $5 \mu \mathrm{m}$ sections were prepared using microtome followed by staining with H\&E. The sections were visualized and photographed at $40 \mathrm{X}$ using digital biological microscope (N120, BR-Biochem Life Sciences, New Delhi, India)[72].

\section{SEM of mammary gland tissue}

The HCl-collagenase and enzymatic digestion methods were used for the purpose of SEM. Small sections of mammary gland tissues treated with HBSS containing $100 \mu \mathrm{g} / \mathrm{ml}$ collagenase (type 4) and $2.5 \mathrm{TRU}$ (turbidity reduction unit) $/ \mathrm{ml}$ of hyaluronidase for $30 \mathrm{~min}$ at $37^{\circ} \mathrm{C}$. After digestion, the tissue was rinsed in the HBSS and then fixed in $4 \%$ glutaraldehyde in $0.1 \mathrm{M}$ cacodylate/ $\mathrm{HCl}$ buffer $(\mathrm{pH} \mathrm{7.2)}$ at room temperature for $3 \mathrm{~h}$. Post fixation was done with $1 \%$ osmium tetraoxide. Tissue sample was subsequently placed in $8 \mathrm{~N} \mathrm{HCl}$ for $30 \mathrm{~min}$ at $60^{\circ} \mathrm{C}$. After $\mathrm{HCI}$ digestion, the tissue was rinsed three times with distilled water to remove the acid. The sample was dried with $70 \%, 80 \%, 90 \%$ and $100 \%$ acetone. All the specimens were dehydrated, dried by the critical point method and examined under SEM(X1000)(JEOL JSM6490LV)[25].

\section{Antioxidant markers}

The mammary gland tissue homogenates $(10 \% \mathrm{w} / \mathrm{v})$ were prepared in $0.15 \mathrm{M} \mathrm{KCl}$ and centrifuged at 10,000 $\mathrm{rpm}$. The supernatants were evaluated for oxidative stress markers, including TBARs, SOD, catalase, GSH and PC using the methods established in our laboratory $[29,73]$.

\section{${ }^{1} \mathrm{H}-\mathrm{NMR}$ based serum metabolomics}

\section{Sample preparation for NMR spectroscopy}

The stored serum samples were thawed at room temperature, $250 \mu \mathrm{l}$ of serum was taken and mixed with $250 \mu \mathrm{l}$ of sodium-phosphate buffer of strength $20 \mathrm{mM}$, $\mathrm{pH} 7.4$ with $0.9 \%$ saline prepared in $\mathrm{D}_{2} \mathrm{O}$ [74](as a cosolvent and to provide a deuterium field/frequency lock). To remove any precipitates or cellular debris, the samples were further centrifuged at 10,000 rpm for $5 \mathrm{~min}$ at room temperature. The clear supernatant fluid of $400 \mu \mathrm{l}$ was finally used in $5 \mathrm{~mm}$ NMR tubes (Wilmad Glass, USA) for data acquisition with a co-axial insert containing the $0.1 \mathrm{mM}$ concentration of TSP (used here as external standard reference to aid spectral calibration). $\mathrm{D}_{2} \mathrm{O}$ and sodium salt of trimethylsilylpropionic acid-d4 (TSP) used for NMR experiments were purchased from SigmaAldrich (Rhode Island, USA).

\section{NMR data acquisition}

The ${ }^{1} \mathrm{H}$ NMR spectra of all the samples were acquired on $800 \mathrm{MHz}$ NMR spectrometer (BrukerAvanceIII) equipped with the cryoprobe at 300 Kelvin (K). On each serum sample, the $1 \mathrm{D}{ }^{1} \mathrm{H}$ transverse relaxation-edited CPMG (Carr-Purcell-Meiboom-Gill) NMR spectra were recorded using the standard Bruker's pulse program library sequence (cpmgpr1d) with pre-saturation of the water peak through irradiating it continuously during the recycle delay (RD) of $5 \mathrm{sec}$. Each spectrum consisted of the 
accumulation of 128 scans and lasted for approximately $15 \mathrm{~min}$. To remove broad signals from proteins and fats, a total spin-spin relaxation time of $60 \mathrm{~ms}(\mathrm{n}=300$ and $2 \tau=200 \mu \mathrm{s}$ ) was applied. Each FID (free induction decay) was zero filled and Fourier-transformed to $64 \mathrm{~K}$ data points following manual phase and baseline-correction. A line broadening factor of $0.3 \mathrm{~Hz}$ and a sine-bell apodization function was applied to FIDs before Fourier Transformation (FT). The raw NMR data were processed using Bruker software Topspin-v2.1 (BrukerBioSpin GmbH, Silberstreifen 476287 Rheinstetten, Germany).

\section{Assignment of the ${ }^{1} \mathrm{H}$ NMR spectra}

The metabolite resonances in the $1 \mathrm{D}{ }^{1} \mathrm{H}$ CPMG NMR spectra were assigned using the Chenomx NMR suite (Chenomx Inc., Edmonton, AB, Canada). The remaining peaks in the $\mathrm{CPMG}{ }^{1} \mathrm{H}$ NMR spectra were assigned as far as possible, by comparing them with the chemical shifts available using previously reported NMR assignments of metabolites [75, 76], data obtained from BMRB database (Biological Magnetic Resonance Data Bank [77] and HMDB (The Human Metabolome Database [78].

\section{Multivariate statistical analysis}

The ${ }^{1} \mathrm{H}$ NMR spectra of all the serum samples were manually phase adjusted and baseline corrected after referencing to the alanine resonance at $\delta(1.46)$ ppm. The CPMG $\delta$ 9.5-0.7 ppm spectra were binned and automatically integrated using AMIX package (Version 3.8.7, Bruker, BioSpin), to reduce the complexity to the NMR data and facilitate pattern recognition. The region distorted due to water suppression $\delta(5.5-4.5) \mathrm{ppm}$, were excluded from the CPMG data set. Finally, the selected regions were reduced to spectral bins of $\delta 0.01 \mathrm{ppm}$. The resultant CPMG, data sets were eventually used for univariate and multivariate analysis in statistical analysis module of MetaboAnalyst, an open access web-based tool for metabolomics studies [79, 80].

Using standard procedures for multivariate statistical analysis in MetaboAnalyst, PCA, PLS-DA, and OPLS-DA were performed on all the groups to get an overview of the grouping trends and to separate the effective treatment dose. The PLS-DA model was further used for pairwise analysis to identify the metabolites responsible for discrimination based on their higher values of variable importance on projection scores (i.e. VIPs $>$ 1). Furthermore, unpaired t-test was applied to assess the significance of change in the metabolic profile and $\mathrm{p}$-value $<0.05$ was used as the criterion for statistical significance. Metabolites meeting the above said criteria were considered to be significant. A 10-fold cross-validation algorithm using the top 5 latent variables, was used which helped to evaluate $100 \%$ classification accuracy, along with the goodness-of fit parameter $\left(\mathrm{R}^{2}\right)$ and the goodness of prediction parameter $\left(\mathrm{Q}^{2}\right)$ values to assess the quality (or predictability) of the models, respectively.

\section{Assay for caspase 3 and caspase 8}

Caspase 3 and caspase 8 fluorometric assays were performed using the methods elaborated in the literature provided with the kits. The assay was carried out in amber colored 96-well plate. Equal volumes of serum sample from both control and experimental animals were diluted with reaction buffer. Dithiothriol (DTT) was added to a final concentration of $10 \mathrm{mM}$. To the reactant mixture $5 \mu \mathrm{l}$ of IETD-AFC/DEVD-AFC substrate was added and incubated for $1 \mathrm{~h}$ at $37^{\circ} \mathrm{C}$. Free AFC levels formed were measured in a plate reader with a $400 \mathrm{~nm}$ excitation and a $505 \mathrm{~nm}$ emission. The results were expressed as fluorescence units/mg of protein [81].

\section{Western blotting}

Total protein lysates were obtained by lysing the mammary gland tissue in RIPA lysis buffer. The protein content was quantified using the Bradford reagent [82]. According to the principles of Laemmli with slight modifications, proteins were resolved on $12.5 \%$ SDSPAGE gel and transferred to PVDF membrane (IPVH 00010 Millipore, Bedford, MA USA. Subsequently, membrane was blocked with 3\% BSA and 3\% not fat milk in TBST for $3 \mathrm{~h}$ and incubated overnight with primary antibody against, Bcl-xl (MA-5-15142), Bcl-2 (SC-7382), BAX (SC-23959), BAD (SC-8044) VDAC (SC-390996), cytochrome c (SC-13561), Apaf-1 (SC-65891), procaspase 9 (SC-73548), NFкBp65 (MA5-1616), UCHL-1 (MA183428), PHD2 (SC-67030), HIF-1 $\alpha$ (SC-13515), FASN (SC-55580), SREBP-1c (SC-13551)at $4^{\circ} \mathrm{C} . \quad \beta$-actin (MA5-15739-HRP) was used as a standard reference. The membrane was washed with TBST thrice and incubated with the corresponding anti-rabbit (SC-2030), anti-goat (SC-2020), anti-mouse (31430, Pierce Thermo Scientific, USA) HRP conjugated secondary antibody (1:5000 dilutions) at room temperature for $3 \mathrm{~h}$. After single TBST wash membranes were developed using an enhanced chemiluminescence substrate (Western Bright ECL HRP substrate, Advansta, Melanopark, California, US) in gel dock system. The quantification of protein was done through densitometry digital analysis of protein bands using Image J software [83, 84].

\section{qRT-PCR}

Primers for real time were designed online using primer quest tool from the IDT DNA technologies website (www.idtdna.com). The amplicon size was kept between 100 to 200 base pairs, GC\% was kept above 50\% and melting temperature was kept between $58^{\circ} \mathrm{C}$ to $62^{\circ} \mathrm{C}$. The specific sequences of the forward and reverse primers are specified in Supplementary Table 3.

Total RNA was extracted from mammary gland tissue using trizol reagent according to the manufacturer's instructions. Briefly, tissues were washed off treatment 
plates using $0.1 \%$ DEPC water. The tissues were crushed in $250 \mu \mathrm{l}$ trizol reagent using micro pestles. Another $750 \mu \mathrm{l}$ of trizol reagent was added to make the final volume to $1 \mathrm{ml}$, followed by addition of $200 \mu \mathrm{l}$ of chloroform and mixing for 2 to $5 \mathrm{~min}$ on a vortex mixer. The suspension was then centrifuged at $14000 \mathrm{rpm}, 4^{\circ} \mathrm{C}$ for $15 \mathrm{~min}$ and upper aqueous phase was gently pipette out in the fresh vials. RNA was precipitated by addition of $500 \mu \mathrm{l}$ chilled isopropanol. The vials were kept at room temperature for $10 \mathrm{~min}$ and were centrifuged at $14000 \mathrm{rpm}, 4^{\circ} \mathrm{C}$ for $10 \mathrm{~min}$ and RNA pellet so obtained was washed twice with $75 \%$ ethanol (chilled) at $7500 \mathrm{rpm}, 4^{\circ} \mathrm{C}$ for $5 \mathrm{~min}$. The RNA pellet was finally dissolved in $15 \mu \mathrm{l}$ of $0.1 \%$ DEPC water. To quantify RNA absorbance was read using nano drop (Qua Well Q5000).

cDNA synthesis was done from $1 \mu \mathrm{g}$ of total mammary gland RNA in a 96 well thermal cycler (BioRad, C1000) with steps including, incubation at $25^{\circ} \mathrm{C}$ for $10 \mathrm{~min}, 37^{\circ} \mathrm{C}$ for $120 \mathrm{~min}, 85^{\circ} \mathrm{C}$ for $5 \mathrm{~min}$ and $4^{\circ} \mathrm{C}$ forever RNA using high capacity cDNA synthesis kit. cDNA sample were quantified using nanodrop and were stored at $-80^{\circ} \mathrm{C}$ until use. $125 \mathrm{ng}$ of cDNA was used as template for each reaction of qRT-PCR with $\beta$-actin as housekeeping control using light cycler 480 machine (Roche Diagnostics, Germany). For each primer pair, a melting curve analysis was performed according to instrument. The program in brief was an initial incubation of $50^{\circ} \mathrm{C}$ for $2 \mathrm{~min}$ hold (UDG incubation) and $95^{\circ} \mathrm{C}$ for 10 min followed by 40 cycles at $95^{\circ} \mathrm{C}$ for $15 \mathrm{~s}$ (denaturation), $58^{\circ} \mathrm{C}$ for $30 \mathrm{~s}$ (annealing) and final extension at $72^{\circ} \mathrm{C}$ for $20 \mathrm{~s}$. Differential expression was calculated by $2-\Delta \Delta \mathrm{CT}$ method. $\beta$-actin was used as internal control and used to normalize ratios between samples $[85,86]$.

\section{Statistical analysis}

All data were presented as mean $\pm \mathrm{SD}$ and analyzed by one-way ANOVA followed by Bonferroni test and for the possible significance identification between the various groups. $* \mathrm{p}<0.05, * * \mathrm{p}<0.01, * * * \mathrm{p}<0.001$ were considered as statistically significant. Statistical analysis was performed using Graph Pad Prism software (5.02).

\section{CONCLUSION}

To conclude, authors would like to submit that ALA ameliorates the morphological, biochemical and associated biological effects of DMBA. As hypothesized, ALA persuaded the mitochondrial mediated death pathway to impede the hypoxic microenvironment and curtail de novo fatty acid synthesis. Our results suggest the possible therapeutic potential of ALA against mammary gland carcinoma without any untoward effect. The study also validates the need of clinical evaluation of ALA for its future use.

\section{ABBREVIATIONS}

ALA- $\alpha$-Linolenic acid; AA-arachidonic acid; AOacridinie orange; AB-alveolar bud; BSA-bovine serum albumin; BMRB- biological magnetic resonance data bank; CPMG- carr-purcell-meiboom-gill; CEC-cuboidal epithelial cell; DHA- docosahexaenoic acid; DMSOdimethyl sulphoxide; DMBA-7, 12-dimethylbenz(a) anthracene; DTT-dithiothriol; DCT- dense connective tissue; EPA-eiconapentanoic acid; EBSS- eagle balanced salt solution; EtBr- ethidium bromide; ECGelectrocardiogram; FBS- fetal bovine serum; FACSflorescence activated cell sorter; FID- free induction decay; FT- fourier transformation; FASN-fatty acid synthase; GSH-glutathione; GPC-glycerophosphocholine; HBSShank's balanced salt solution; H\&E- hematoxylin \& eosin; HRV- heart rate variability; HR- heart rate; HMBD- the human metabolome database; HF- high frequency; HIF$1 \alpha$ - hypoxia inducible factor- $1 \alpha$; LF- low frequency; LCTloose connective tissue; LDL- low density lipoprotein; MTT- 3-(4, 5-Dimethyl-2-thiazolyl)-2, 5-diphenyl-2Htetrazolium bromide; MPTP- mitochondria permeability transition pore; MEC- mypepithelial cell; NAG- N-acetyl glycoprotein; OAG- O-acetyl glycoprotein; PUFApolyunsaturated fatty acid; PI- propidium iodide; PSphosphatidylserine; PC- phosphocholine; PCA- principal component analysis; PLS-DA- partial least squares discriminant analysis; PHD2- prolyl hydroxylase-2; RD- recycle delay; ROS- reactive oxygen species; SEM- scanning electron microscope; SOD- superoxide dismutase; TMX- tamoxifen citrate; TRU- turbidity reduction unit; TBARs- thiobarbituric acid reactive substances; TSP- trimethylsilylpropionic acid-d4; VLFvery low frequency, VLDL- very low density lipoprotein

\section{Author contributions}

SR carried out the bench work; AR performed the NMR metabolic studies; SRS performed the qRT-PCR studies; MS, UD, SG and RKY performed the carmine staining, histopathology and SEM analysis; LS and JKR performed the caspase 3 and caspase8 assay; VK, MNA and ASS: performed the statistical studies and compiled the data; RP supervise the qRT-PCR studies; DK evaluate the results of NMR metabolic studies; GK perceived the idea, designed and supervised the whole study, prepared and proof read the final manuscript.

\section{ACKNOWLEDGMENTS}

The author would like to thanks, University Grants Commission, Government of India for granting senior research fellowship to MS, JKR, and SG. Authors are also thankful to Department of Science and Technology, Government of India for giving senior research fellowship SR. Thanks are also due to Dr. Anand Prakash, Department 
of Biotechnology for providing the facility of Gel Dock system.

\section{CONFLICTS OF INTEREST}

Authors declare no competing interest.

\section{FUNDING}

The work presented in the manuscript supported through the grant (SB/EMEQ-254/2013) from Department of Science and Technology, Government of India sanctioned to Dr. Gaurav Kaithwas.

\section{REFERENCES}

1. Swanson D, Block R, Mousa SA. Omega-3 fatty acids EPA and DHA: health benefits throughout life. Adv Nutr. 2012; 3: $1-7$.

2. Welch AA, Shakya-Shrestha S, Lentjes MA, Wareham NJ, Khaw KT. Dietary intake and status of $n-3$ polyunsaturated fatty acids in a population of fish-eating and non-fish-eating meat-eaters, vegetarians, and vegans and the precursorproduct ratio of $\alpha$-linolenic acid to long-chain $n-3$ polyunsaturated fatty acids: results from the EPIC-Norfolk cohort. Am J Clin Nutr. 2010; 92: 1040-51.

3. Kinney AJ, Cahoon EB, Damude HG, Liu ZB. Production of very long chain polyunsaturated fatty acids in oilseed plants. Google Patents. Publication numberUS20040172682A1, publication date-2 Sep 2004.

4. Calder PC. The role of marine omega-3 (n-3) fatty acids in inflammatory processes, atherosclerosis and plaque stability. Mol Nutr Food Res. 2012; 56: 1073-80.

5. Wall R, Ross RP, Fitzgerald GF, Stanton C. Fatty acids from fish: the anti-inflammatory potential of long-chain omega-3 fatty acids. Nutr Rev. 2010; 68: 280-9.

6. Yadav S, Tiwari V, Singh M, Yadav RK, Roy S, Devi U, Gautam S, Rawat JK, Ansari MN, Saeedan AS, Kaithwas G. Comparative efficacy of alpha-linolenic acid and gammalinolenic acid to attenuate valproic acid-induced autism-like features. J Physiol Biochem. 2016: 1-12.

7. Alexander W. Prostate cancer risk and omega-3 fatty acid intake from fish oil. P T. 2013; 38: 561-564.

8. MacLennan M, Ma DW. Role of dietary fatty acids in mammary gland development and breast cancer. Breast Cancer Res. 2010; 12: 211.

9. Goyal A, Sharma V, Upadhyay N, Gill S, Sihag M. Flax and flaxseed oil: an ancient medicine \& modern functional food. J Food Sci Technol. 2014; 51: 1633-53.

10. Ayala A, Muñoz MF, Argüelles S. Lipid peroxidation: production, metabolism, and signaling mechanisms of malondialdehyde and 4-hydroxy-2-nonenal. Oxid Med Cell Longev. 2014; 2014: 360438.
11. Sundarraj S, Thangam R, Sreevani V, Kaveri K, Gunasekaran P, Achiraman S, Kannan S. $\gamma$-Sitosterol from Acacia nilotica L. induces $\mathrm{G} 2 / \mathrm{M}$ cell cycle arrest and apoptosis through c-Myc suppression in MCF-7 and A549 cells. J Ethnopharmacol. 2012; 141: 803-9.

12. Qiu Y, Liu Y, Wang L, Xu L, Bai R, Ji Y, Wu X, Zhao Y, Li Y, Chen C. Surface chemistry and aspect ratio mediated cellular uptake of Au nanorods. Biomaterials. 2010; 31 : 7606-19.

13. Alam IS, Neves AA, Witney TH, Boren J, Brindle KM. Comparison of the $\mathrm{C} 2 \mathrm{~A}$ domain of synaptotagmin-I and annexin-V as probes for detecting cell death. Bioconjug Chem. 2010; 21: 884-91.

14. Choi EJ, Kim GH. Anticancer mechanism of equol in 7, 12-dimcthylbenz (a) anthracene-treated animals. Int J Oncol. 2011; 39: 747.

15. Hakkak R, Holley AW, MacLeod SL, Simpson PM, Fuchs GJ, Jo CH, Kieber-Emmons T, Korourian S. Obesity promotes 7, 12-dimethylbenz (a) anthracene-induced mammary tumor development in female zucker rats. Breast Cancer Res. 2005; 7: R627.

16. Gao J, Lauer FT, Dunaway S, Burchiel SW. Cytochrome $\mathrm{P} 450$ 1B1 is required for 7, 12-dimethylbenz (a)-anthracene (DMBA) induced spleen cell immunotoxicity. Toxicol Sci. 2005; 86: 68-74.

17. Peel AB, Thomas SM, Dittus K, Jones LW, Lakoski SG. Cardiorespiratory fitness in breast cancer patients: a call for normative values. J Am Heart Assoc. 2014; 3: e000432.

18. Kongbundansuk S, Hundley WG. Noninvasive imaging of cardiovascular injury related to the treatment of cancer. JACC Cardiovasc Imaging. 2014; 7: 824-38.

19. Wang YM, Wu HT, Huang EY, Kou YR, Hseu SS. Heart rate variability is associated with survival in patients with brain metastasis: a preliminary report. Biomed Res Int. 2013; 503421: 6 .

20. Hall WL, Hay G, Maniou Z, Seed PT, Chowienczyk PJ, Sanders TA. Effect of low doses of long chain n-3 polyunsaturated fatty acids on sleep-time heart rate variability: a randomized, controlled trial. Int J Cardiol. 2013; 168: 4439.

21. Hanahan D, Weinberg RA. Hallmarks of cancer: the next generation. Cell. 2011; 144: 646-74.

22. Plante I, Stewart MK, Laird DW. Evaluation of mammary gland development and function in mouse models. J Vis Exp. 2011: e2828.

23. Manral C, Roy S, Singh M, Gautam S, Yadav RK, Rawat JK, Devi U, Ansari MN, Saeedan AS, Kaithwas G. Effect of $\beta$-sitosterol against methyl nitrosourea-induced mammary gland carcinoma in albino rats. BMC Complement Altern Med. 2016; 16: 260.

24. Rani A, Roy S, Singh M, Devi U, Yadav RK, Gautam S, Rawat JK, Ansari MN, Saeedan AS, Prakash A, Kaithwas G. $\alpha$-Chymotrypsin regulates free fatty acids and UCHL- 1 to 
ameliorate N-methyl nitrosourea induced mammary gland carcinoma in albino wistar rats. Inflammopharmacology. 2016; 24: 277-86.

25. Yoshida H, Yoshida A, Fukunishi R, Nagato T, Uehara Y. Scanning electron microscopy of 7, 12-dimethylbenz (a)-anthracene-induced mammary carcinoma in the female Sprague-Dawley rat. Virchows Arch B Cell Pathol Incl Mol Pathol. 1980; 32: 105.

26. Sharma P, Jha AB, Dubey RS, Pessarakli M. Reactive oxygen species, oxidative damage, and antioxidative defense mechanism in plants under stressful conditions. J Bot. 2012; 217037: 26.

27. Bhattacharyya A, Chattopadhyay R, Mitra S, Crowe SE. Oxidative stress: an essential factor in the pathogenesis of gastrointestinal mucosal diseases. Physiol Rev. 2014; 94: 329-54.

28. Shah D, Mahajan N, Sah S, Nath SK, Paudyal B. Oxidative stress and its biomarkers in systemic lupus erythematosus. J Biomed Sci. 2014; 21: 23.

29. Raj P, Singh M, Rawat JK, Gautam S, Saraf SA, Kaithwas G. Effect of enteral administration of $\alpha$-linolenic acid and linoleic acid against methotrexate induced intestinal toxicity in albino rats. RSC Adv. 2014; 4: 60397-403.

30. Asgari Y, Zabihinpour Z, Salehzadeh-Yazdi A, Schreiber F, Masoudi-Nejad A. Alterations in cancer cell metabolism: the Warburg effect and metabolic adaptation. Genomics. 2015; 105: 275-81.

31. Romero-Garcia S, Moreno-Altamirano MM, Prado-Garcia H, Sánchez-García FJ. Lactate contribution to the tumor microenvironment: mechanisms, effects on immune cells and therapeutic relevance. Front Immunol. 2016; 16: 7: 52.

32. Beloribi-Djefaflia S, Vasseur S, Guillaumond F. Lipid metabolic reprogramming in cancer cells. Oncogenesis. 2016; 5: e189.

33. Huang S, Chong N, Lewis NE, Jia W, Xie G, Garmire LX. Novel personalized pathway-based metabolomics models reveal key metabolic pathways for breast cancer diagnosis. Genome Med. 2016; 8: 34.

34. Tang X, Lin CC, Spasojevic I, Iversen ES, Chi JT, Marks JR. A joint analysis of metabolomics and genetics of breast cancer. Breast Cancer Res. 2014; 16: 415.

35. Guleria A, Pratap A, Dubey D, Rawat A, Chaurasia S, Sukesh E, Phatak S, Ajmani S, Kumar U, Khetrapal CL. NMR based serum metabolomics reveals a distinctive signature in patients with Lupus Nephritis. Sci Rep. 2016; 6: 35309 .

36. Afzali B, Bakri RS, Bharma-Ariza P, Lumb PJ, Dalton N, Turner NC, Wierzbicki AS, Crook MA, Goldsmith DJ. Raised plasma total sialic acid levels are markers of cardiovascular disease in renal dialysis patients. J Nephrol. 2003; 16: 540-5.

37. Baumann H, Jahreis GP, Gaines KC. Synthesis and regulation of acute phase plasma in primary cultures of mouse hepatocytes. J Cell Biol. 1983; 97: 866-76.
38. Anand R, Kaithwas G. Anti-inflammatory potential of alpha-linolenic acid mediated through selective COX inhibition: computational and experimental data. Inflammation. 2014; 37: 1297-306.

39. Geiger R, Rieckmann JC, Wolf T, Basso C, Feng Y, Fuhrer T, Kogadeeva M, Picotti P, Meissner F, Mann M. L-arginine modulates $\mathrm{T}$ cell metabolism and enhances survival and anti-tumor activity. Cell. 2016; 167:829-842.

40. Lala PK, Chakraborty C. Role of nitric oxide in carcinogenesis and tumour progression. Lancet Oncol. 2001; 2: 149-56.

41. Lind DS. Arginine and cancer. J Nutr. 2004; 134: 2837S-41S.

42. Nakada HI, Friedmann B, Weinhouse S. Pathways of glycine catabolism in rat liver. J Biol Chem. 1955; 216: 583-92.

43. Pistritto G, Trisciuoglio D, Ceci C, Garufi A, D'Orazi G. Apoptosis as anticancer mechanism: function and dysfunction of its modulators and targeted therapeutic strategies. Aging (Albany NY). 2016; 8: 603. https://doi. org/10.18632/aging.100934.

44. Camara AK, Lesnefsky EJ, Stowe DF. Potential therapeutic benefits of strategies directed to mitochondria. Antioxid Redox Signal. 2010; 13: 279-347.

45. Sinha D, D'silva P. Chaperoning mitochondrial permeability transition: regulation of transition pore complex by a J-protein, DnaJC15. Cell Death Dis. 2014; 5: e1101.

46. Bratton SB, Salvesen GS. Regulation of the Apaf-1caspase-9 apoptosome. J Cell Sci. 2010; 123: 3209-14.

47. McIlwain DR, Berger T, Mak TW. Caspase functions in cell death and disease. Cold Spring Harb Perspect Biol. 2013; 5: a008656.

48. Chai J, Shi Y. Apoptosome and inflammasome: conserved machineries for caspase activation. Natl Sci Rev. 2014; 1 : 101-18.

49. Shi Y. Caspase activation, inhibition, and reactivation: a mechanistic view. Protein Sci. 2004; 13: 1979-87.

50. Akbar M, Kim HY. Protective effects of docosahexaenoic acid in staurosporine-induced apoptosis: involvement of phosphatidylinositol-3 kinase pathway. J Neurochem. 2002; 82: 655-65.

51. Wu Y, Tada M, Takahata K, Tomizawa K, Matsui H. Inhibitory effect of polyunsaturated fatty acids on apoptosis induced by etoposide, okadaic acid and AraC in Neuro2a cells. Acta Med Okayama. 2007; 61: 147-52.

52. Graziano F, Ruzzo A, Giacomini E, Ricciardi T, Aprile G, Loupakis F, Lorenzini P, Ongaro E, Zoratto F, Catalano V. Glycolysis gene expression analysis and selective metabolic advantage in the clinical progression of colorectal cancer. Pharmacogenomics J. 2017; 17: 258-64.

53. Yeh IJ, Ogba N, Bensigner H, Welford SM, Montano MM. HEXIM1 down-regulates hypoxia-inducible factor- $1 \alpha$ protein stability. Biochem J. 2013; 456: 195-204. 
54. Zaytseva YY, Harris JW, Mitov MI, Kim JT, Butterfield DA, Lee EY, Weiss HL, Gao T, Evers BM. Increased expression of fatty acid synthase provides a survival advantage to colorectal cancer cells via upregulation of cellular respiration. Oncotarget. 2015; 6: 18891-904. https:// doi.org/10.18632/oncotarget.3783.

55. Feng Z, Levine AJ. The regulation of energy metabolism and the IGF-1/mTOR pathways by the $\mathrm{p} 53$ protein. Trends Cell Biol. 2010; 20: 427-34.

56. Harada H. Hypoxia-inducible factor 1-mediated characteristic features of cancer cells for tumor radioresistance. J Radiat Res. 2016; 57: i99-i105.

57. Laliotis G, Bizelis I, Rogdakis E. Comparative approach of the de novo fatty acid synthesis (lipogenesis) between ruminant and non ruminant mammalian species: from biochemical level to the main regulatory lipogenic genes. Curr Genomics. 2010; 11: 168-83.

58. Sato R. Sterol metabolism and SREBP activation. Arch Biochem Biophys. 2010; 501: 177-81.

59. Palozza P, Sgarlata E, Luberto C, Piccioni E, Anti M, Marra G, Armelao F, Franceschelli P, Bartoli GM. n-3 fatty acids induce oxidative modifications in human erythrocytes depending on dose and duration of dietary supplementation. Am J Clin Nutr. 1996; 64: 297-304.

60. Bartoli G, Palozza P, Luberto C, Franceschelli P, Piccioni E. Dietary fish oil inhibits human erythrocyte $\mathrm{Mg}, \mathrm{NaK}$ ATPase. Biochem Biophys Res Commun. 1995; 213: 881-7.

61. Park Y, Albright KJ, Liu W, Storkson JM, Cook ME, Pariza MW. Effect of conjugated linoleic acid on body composition in mice. Lipids. 1997; 32: 853-8.

62. Schubert R, Kitz R, Beermann C, Rose MA, Baer PC, Zielen S, Boehles H. Influence of low-dose polyunsaturated fatty acids supplementation on the inflammatory response of healthy adults. Nutrition. 2007; 23: 724-30.

63. Chou CC, Yang JS, Lu HF, Ip SW, Lo C, Wu CC, Lin JP, Tang NY, Chung JG, Chou MJ. Quercetin-mediated cell cycle arrest and apoptosis involving activation of a caspase cascade through the mitochondrial pathway in human breast cancer MCF-7 cells. Arch Pharm Res. 2010; 33: 1181-91.

64. Liao XH, Lu DL, Wang N, Liu LY, Wang Y, Li YQ, Yan TB, Sun $\mathrm{XG}, \mathrm{Hu} \mathrm{P}$, Zhang TC. Estrogen receptor $\alpha$ mediates proliferation of breast cancer MCF-7 cells via a $\mathrm{p} 21 / \mathrm{PCNA} /$ E2F1-dependent pathway. FEBS J. 2014; 281: 927-42.

65. Murugan K, Dinesh D, Kavithaa K, Paulpandi M, Ponraj T, Alsalhi MS, Devanesan S, Subramaniam J, Rajaganesh R, Wei H. Hydrothermal synthesis of titanium dioxide nanoparticles: mosquitocidal potential and anticancer activity on human breast cancer cells (MCF-7). Parasitol Res. 2016; 115: 1085-96.

66. Shrivastava S, Jeengar MK, Reddy VS, Reddy GB, Naidu $\mathrm{V}$. Anticancer effect of celastrol on human triple negative breast cancer: possible involvement of oxidative stress, mitochondrial dysfunction, apoptosis and PI3K/Akt pathways. Exp Mol Pathol. 2015; 98: 313-27.
67. Dozio E, Ruscica M, Passafaro L, Dogliotti G, Steffani L, Pagani A, Demartini G, Esposti D, Fraschini F, Magni P. The natural antioxidant alpha-lipoic acid induces p27 Kip1dependent cell cycle arrest and apoptosis in MCF-7 human breast cancer cells. Eur J Pharmacol. 2010; 641: 29-34.

68. Noguchi M, Minami M, Yagasaki R, Kinoshita K, Earashi M, Kitagawa H, Taniya T, Miyazaki I. Chemoprevention of DMBA-induced mammary carcinogenesis in rats by lowdose EPA and DHA. Br J Cancer. 1997; 75: 348.

69. Kmecova J, Klimas J. Heart rate correction of the QT duration in rats. Eur J Pharmacol. 2010; 641: 187-92.

70. Pereira-Junior PP, Marocolo M, Rodrigues FP, Medei E, Nascimento JH. Noninvasive method for electrocardiogram recording in conscious rats: feasibility for heart rate variability analysis. An Acad Bras Cienc. 2010; 82: 431-7.

71. De Assis S, Warri A, Cruz MI, Hilakivi-Clarke L. Changes in mammary gland morphology and breast cancer risk in rats. J Vis Exp. 2010: e2260-e.

72. Sorenmo K, Rasotto R, Zappulli V, Goldschmidt M. Development, anatomy, histology, lymphatic drainage, clinical features, and cell differentiation markers of canine mammary gland neoplasms. Vet Pathol. 2011; 48: 85-97.

73. Tiwari V, Singh M, Rawat JK, Devi U, Yadav RK, Roy S, Gautam S, Saraf SA, Kumar V, Ansari N, Kaithwas G. Redefining the role of peripheral LPS as a neuroinflammatory agent and evaluating the role of hydrogen sulphide through metformin intervention. Inflammopharmacology. 2016; 24: 253-64.

74. Sheedy JR, Ebeling PR, Gooley PR, McConville MJ. A sample preparation protocol for $1 \mathrm{H}$ nuclear magnetic resonance studies of water-soluble metabolites in blood and urine. Anal Biochem. 2010; 398: 263-5.

75. Guleria A, Bajpai NK, Rawat A, Khetrapal CL, Prasad N, Kumar D. Metabolite characterisation in peritoneal dialysis effluent using high-resolution $1 \mathrm{H}$ and $1 \mathrm{H}-13 \mathrm{C}$ NMR spectroscopy. Magn Reson Chem. 2014; 52: 475-9.

76. Guleria A, Misra DP, Rawat A, Dubey D, Khetrapal CL, Bacon P, Misra R, Kumar D. NMR-based serum metabolomics discriminates Takayasu arteritis from healthy individuals: a proof-of-principle study. J Proteome Res. 2015; 14: 3372-81.

77. Ulrich EL, Akutsu H, Doreleijers JF, Harano Y, Ioannidis YE, Lin J, Livny M, Mading S, Maziuk D, Miller Z. BioMagResBank. Nucleic Acids Res. 2008; 36: D402-D8.

78. Wishart DS, Tzur D, Knox C, Eisner R, Guo AC, Young N, Cheng D, Jewell K, Arndt D, Sawhney S. HMDB: the human metabolome database. Nucleic Acids Res. 2007; 35 : D521-D6.

79. Xia J, Sinelnikov IV, Han B, Wishart DS. MetaboAnalyst 3.0â€"making metabolomics more meaningful. Nucleic Acids Res. 2015; 1: W251-W7.

80. Xia J, Psychogios N, Young N, Wishart DS. MetaboAnalyst: a web server for metabolomic data analysis and interpretation. Nucleic Acids Res. 2009; 37: W652-W60. 
81. Alikhani M, Alikhani Z, Raptis M, Graves DT. TNF- $\alpha$ in vivo stimulates apoptosis in fibroblasts through caspase- 8 activation and modulates the expression of pro-apoptotic genes. J CellPhysiol. 2004; 201: 341-8.

82. Ernst $\mathrm{O}$, Zor T. Linearization of the bradford protein assay. J Vis Exp. 2010: 1918

83. Wang J, Jenkins S, Lamartiniere CA. Cell proliferation and apoptosis in rat mammary glands following combinational exposure to bisphenol A and genistein. BMC Cancer. 2014; 14: 379 .

84. Shao Y, Wellman TL, Lounsbury KM, Zhao FQ. Differential regulation of GLUT1 and GLUT8 expression by hypoxia in mammary epithelial cells. Am J Physiol Regul Integr Comp Physiol. 2014; 307: R237-R47.

85. Park J, Schwarzbauer JE. Mammary epithelial cell interactions with fibronectin stimulate epithelialmesenchymal transition. Oncogene. 2014; 33: 1649-57.

86. Zhou W, Shi G, Zhang Q, Wu Q, Li B, Zhang Z. MicroRNA-20b promotes cell growth of breast cancer cells partly via targeting phosphatase and tensin homologue (PTEN). Cell Biosci. 2014; 4: 62. 